Research Article

\title{
Optimal Skyhook and Groundhook Control for Semiactive Suspension: A Comprehensive Methodology
}

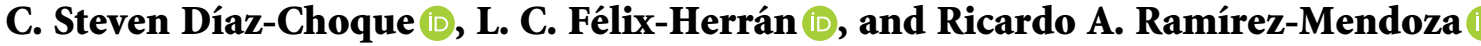 \\ Tecnologico de Monterrey, School of Engineering and Sciences, Monterrey 64849, Mexico \\ Correspondence should be addressed to C. Steven Díaz-Choque; a01757397@itesm.mx
}

Received 21 July 2021; Revised 20 September 2021; Accepted 24 September 2021; Published 7 December 2021

Academic Editor: Vasudevan Rajamohan

Copyright (c) 2021 C. Steven Díaz-Choque et al. This is an open access article distributed under the Creative Commons Attribution License, which permits unrestricted use, distribution, and reproduction in any medium, provided the original work is properly cited.

\begin{abstract}
This manuscript establishes a methodology that guides the designers to develop an optimal controller for a semiactive suspension system. The methodology's processes are generally explained and straightforwardly, so a designer can extrapolate the methodology to a specific problem. Furthermore, this research presents an optimal control strategy for a semiactive control applied to a quarter vehicle model as an example of using the methodology. A particular interest is made in the advantages of such a simple synthesis and in the compromises that must be done in skyhook and groundhook control law applications. This manuscript exposes a logical and straightforward approach for choosing the controllers' design parameters; also, efforts must be made to express precise performance specifications and constraints in the control design. The herein methodology could be relevant in the process design for intelligent suspensions, from one-quarter toward the entire vehicle.
\end{abstract}

\section{Introduction}

The study of vehicle suspensions to improve comfort and stability is a topic that has been and continues to be widely explored and analyzed to propose control solutions that improve performance indexes. The main role of suspensions is to improve comfort by isolating the vehicle chassis from uneven ground profiles while providing good road holding to ensure passenger safety. In this context, suspensions that guarantee this behavior are of high interest in the automotive industry. The design of suspensions that allow meeting performance objectives for comfort and stability demands a challenging endeavor in modeling and control and can be addressed for a one-quarter, a half, or the full vehicle suspension. Each case has its relevance and contribution to solve the problem.

There are three types of suspensions: passive, active, and semiactive. Passive suspensions are found in typical commercial vehicles; their characteristics remain fixed so that they always provide the same passenger comfort and the same road holding. In other words, their nature does not vary in real time, and it is not possible to apply suspension control with them. However, with a higher cost, some luxurious and sports vehicles include a particular type of suspensions, active or semiactive, whose characteristics vary in real time. This attribute allows achieving better comfort and road holding.

Of the nonpassive options, semiactive suspensions with magnetorheological dampers have proven affordable, effective, and safe when integrated into the vehicle. The semiactive suspensions include magnetorheological (MR) [1] or electrorheological (ER) [2] adjustable dampers, which are also the most applied actuators because of their safeness, significantly lower power consumption, quick transient-time response, and easy installation [3]. However, the nonlinear phenomena presented in the damper's characteristics increase the system's study complexity $[4,5]$.

The study of a one-quarter vehicle allows identifying the impact of the road profile vibrations on the masses. Although the system is limited to vertical dynamics, it includes the interaction of the shock absorber with the masses of the chassis and suspension so that a control system can be analyzed and designed. Therefore, suspension control of 
one-quarter vehicle suspension has been widely explored and studied to improve passenger comfort and the so-called road holding.

For more than two decades, so many different control strategies have been applied, and it is not easy to list all of them in a single state-of-the-art review. Each reported result contributes to the solution of the problem and, at the same time, opens the possibility of investigating areas of opportunity in this line to improve suspension performance. The state-of-the-art revision is limited to the application of control techniques for semiactive suspensions that represent the vertical dynamics of $1 / 4$ of a vehicle and use a magnetorheological damper as an actuator. In addition, the included references are those reported in the last five years, which, in most cases, are the most recent reported improvements of other strategies that have been applied before.

One line of research includes fuzzy controllers, whose most recent results are a fuzzy PID [6] and a fuzzy-based dynamic inversion controller [7]. Other strategies have also been applied, such as a Fuzzy-Neural Networks controller with Particle Swarm Optimization [8], an optimization effort using firefly and particle swarm [9], and a fuzzy controller with a correction factor applied to a vehicle suspension with a Shear-Valve Mode MR damper [10].

Additional control strategies have generated results that improve the performance of the passive suspension. Recent reported outcomes include a multiple positive position feedback [11], cascade quantitative feedback controller [12], state-observer-based Takagi-Sugeno fuzzy controller (SOTSFC) [13], linear active disturbance rejection control (LADRC) [14], and an active disturbance rejection control (ADRC) [15]. Fault-tolerant control strategies have also been applied [16], along with sliding mode controllers (SMCs). Among these reported outcomes, it highlights a PID for disturbance compensation with a sliding mode module for disturbance estimation errors [17] and a second-order sliding mode controller as an improvement to reduce the chattering observed in traditional sliding mode control [18]. In this last outcome, the simulation scenario included robustness under masses uncertainties.

Sometimes, specially tailored MR dampers have been designed and manufactured to achieve better performance with control strategies. For example, there are reported results of a pure Artificial Neural Network applied to a new low-cost design of MR damper [19] and a new MR damper with nanotubes employed to design and implement an optimal-PID control [20]. In both cases, the concept of a semiactive suspension with an MR damper was maintained, although with a different physical design. Whether with commercial MR dampers or with dampers manufactured for particular experiments, the proposed solutions have been compared against the performance of strategies such as hybrid (skyhook + groundhook), pure skyhook, Ho, traditional fuzzy controllers, and in general against the passive suspension.

One set of controllers that have given acceptable results and much recent work is the approach of the skyhook, groundhook, or a combination of both (hybrid). These control strategies have generated results where the overall suspension performance is improved when compared against a passive suspension [21-23]. On some occasions, controllers such as fuzzy ones are fused with the hybrid approach, and a hybrid fuzzy PID-like controller has been reported with results in the event of a road bump disturbance [24] and a fuzzy skyhook with results in the frequency domain [25]. Also, an improvement in the performance of a hybrid controller has also been reported using lookup tables [26].

In the different control strategies investigated, an effort has been made to optimize a performance index as the minimization of root-mean-quad weighted acceleration [27] or the use of an optimal feedback controller through linear quadratic approaches [28-30]. In this last approach, the control strategy was complemented with an inverse model of the MR damper and Artificial Neural Networks. Also, in optimization, a fractional-order proportional-integral-derivative (FOPID) controller has been reported where the tuning of the controller was performed using the NelderMead optimization algorithm [31].

A research line that has generated outstanding results versus the passive suspension considers the hybrid strategy (a combination of skyhook and groundhook) reinforced with optimization characteristics. A semiactive suspension has been reported with a hybrid control that uses a sensitivity analysis and the one-factor-at-a-time method to calculate optimal parameters and adjust gains in real time [32]. Previously, a modification to the skyhook control focused on minimizing the acceleration of the suspended mass was reported. This skyhook controller with optimization characteristics has been denominated Acceleration-DrivenDamper (ADD) [33]. In addition, optimal versions have been reported for the skyhook controller, e.g., an optimal skyhook complemented with a minimum order observer to estimate the state of mass velocities to reduce the implementation cost by employing only one sensor [34].

Furthermore, an extension of that work has been reported, and it includes the three control approaches: skyhook, groundhook, and hybrid, for the same case study; this allowed a comparison of the performance of the three approaches [35]. Furthermore, reported works that have applied optimal oriented skyhook, groundhook, or hybrid controllers have achieved better performance than a reference passive suspension and semiactive suspensions with diverse control strategies; however, a possibility of improving the design process has been detected.

The main difficulty for novice engineers when starting in the design of a vehicle suspension control model is to know the steps that lead them to the appropriate results; furthermore, most of the studies do not present their methodologies and just their mathematical models, simulations, and results. Besides, a problem to be concerned about is obtaining the appropriate controller parameters. As explained before, some works attempt to obtain an optimal controller parameter and minimize a cost function; however, in these cases, the suspension behavior is unknown when different controller values are applied; therefore, this work proposes a methodology to select the constants of the hybrid controller toward the optimization of a single performance 
criterion. The selected criterion is part of the set of analyzed standards to measure passenger comfort and vehicle stability.

The main contribution is the proposal of a design methodology that develops control surfaces to choose the most appropriate parameters that maximize/minimize a performance criterion and facilitate the controller's tuning. This methodology considers the performance requirements of the suspension and the associated design restrictions, e.g., the suspension stroke (the available space between the sprung and unsprung masses). The case study is a onequarter vehicle suspension where nonlinear control strategies, such as skyhook, groundhook, and hybrid, are applied. The performance of the studied vehicle suspension, whose controller has been tuned through the control surfaces approach, is compared against a passive suspension model in time and frequency domains. Furthermore, the results are compared against reported works [36, 37]. These outcomes include similar performance criteria, suspension models, and control techniques; thus, it is a fair comparison.

The outline of the article is as follows. Section 1 includes the problem statement, the motivation, the state-of-the-art revision, and the contribution. Section 2 explains the design methodology. Section 3 develops a one-quarter vehicle model. Section 4 introduces the performance criteria. Section 5 presents the controller design. Section 6 introduces the road disturbances. Section 7 gives simulation and results. Finally, conclusions and future perspectives are given in Section 8.

\section{Methodology}

This research presents a methodology to design an optimal controller for a semiactive suspension system. Figure 1 shows the general steps that the designer should follow to design and implement an appropriate controller. The steps are explained in the following list:

(1) Select the controller to be implemented and determine all the benefits that it incorporates, e.g., degree of vibration isolation from road roughness, comfort and handling improvement, and resonance avoidance of vehicle and human sensibility. Recent control approaches (skyhook, fuzzy, Neural Network, SMC, PID, among others) were mentioned in Section 1.

(2) Establish the structural vehicle's components, e.g., masses, inertias, and degrees of freedom for the suspension's representation. From a one-quarter suspension, including more dynamics with a onehalf vehicle to a more complete analysis by applying the four-wheel vehicle, keeping in mind that having more degrees of freedom increases the study complexity.

(3) Establish the vehicle's dynamic model and determine the characteristics of every employed component, e.g., damper's attributes (viscoelastic, hysteresis, and saturation), suspension stiffness, sprung and unsprung masses, suspension stroke, among others.
(4) Design the mathematical representation of the mechanical behavior following Newton's Laws and the differential equations that model the phenomena. Furthermore, include the mathematical formulation to design the selected controller (i.e., fuzzy logic and space state representation).

(5) The physical parameters as the damping, stiffness properties, and masses must be set based on the vehicle to be analyzed. These physical parameters can be chosen from reported work; however, it is essential to work with real characterized parameters thinking about a possible future controller implementation.

(6) The vehicle dynamics simulations with the controller should be developed in specialized software like Simulink $^{\mathrm{TM}}$, Matlab ${ }^{\mathrm{TM}}$, or CARSim ${ }^{\mathrm{TM}}$ to have more reliable results and to be closer to the physical suspension system.

(7) Carry out a synthesis of the results. The findings are analyzed based on some performance criteria presented in previous work. Moreover, the achieved performance obtained with the optimal controller is compared with the results obtained by a passive suspension system and under the same simulation conditions.

For the sake of simplicity, a particular case is presented. This work starts by choosing skyhook, groundhook, and hybrid controller techniques based on their benefits and qualities for a suspension system. Then, this research employs a one-quarter vehicle suspension as the case of the study; however, it is possible to replicate the methodology to complex models toward the four-wheel vehicle suspension. Furthermore, this research establishes the vehicle dynamics involved; the case of the study includes an MR damper, so it is necessary to include its nonlinearities. Then, the mathematical model representation based on Newton's second law is used to determine the correspondent outputs like chassis displacement and acceleration and tire displacement. Then, the physical parameters were obtained from $[38,39]$, so a most novel vehicle representation is simulated. Finally, the simulation is carried out, and the vehicle response is analyzed. This investigation attempts to obtain an optimal controller by designing a decision control surface as presented in Figure 2, where the dependent axis is the performance criteria. In contrast, the independent axis is the controller parameter. A more accurate explanation of the rationality behind this controller surface is given later in this report.

\section{One-Quarter Vehicle Model}

In this manuscript, a quarter vehicle's suspension model is considered with an MR damper (see Figure 3). In real applications, the semiactive damper is not "ideal" and the available active force $u$ is constrained by upper and lower values, both depending on the suspension deflection speed. For the theoretical scenario, the control designers consider the semiactive damper as an "ideal" actuator. It means with no limits in the delivered values and its bandwidth. 
Those "ideal" considerations about the limited force will deteriorate the results obtained when a full active actuator is considered during the control design step. In the automotive industry, MR dampers are increasingly used to design semiactive suspension systems. This damper class provides a fast, smooth, and continuously variable damping coefficient with a wide range of available forces preserving low power consumption [46]. The range of adjustability is virtually within the saturation state, making MR damper technology an excellent replacement for conventional suspension dampers. The MR damper working principle can be expressed according to [38]. With an MR damper, the fluid viscosity changes by adjusting the magnetic field intensity provided by a self-inductance located at the piston's extremity. When a magnetic field is created, the fluid particles are aligned and oppose the fluid movement, increasing the damping coefficient. MR damper working principle can be expressed when a magnetic field is applied, and the particles are aligned (zoom on the piston extremity). Empirical equations describing MR damper behavior are complex. Hence, a common way to model these dampers' responses is given by the static speed-force actuator map, which describes the set of forces that the MR damper can provide [38].

The MR damper is modeled based on the Bouc-Wen approach [4], as shown in Figure 3. Besides, it is possible to change the Bouc-Wen model for any other model that generates a force $F_{d}$. In the model, $m_{s}$ represents the sprung mass and $m_{u s}$ the unsprung mass. The wheel tire is modeled by a spring with the stiffness coefficient $k_{u s}$ and $k_{s}$ represents the constant of the suspension' spring. Using the MR damper, the model becomes nonlinear because of the hysteresis and viscoplasticity characteristics of the damper's fluid [5]. $k_{0}$ represents stiffness, $c_{0}$ represents viscous damping, and $\alpha$ represents the hysteresis. $z_{s}$ represents the displacement of the quarter of the chassis mass, $z_{u s}$ represents the displacement of the tires, and $z_{r}$ represents the disturbance input from the road surface. It is assumed that the wheel-road contact is ensured. The differential equations (1) and (2) represent the vertical dynamic of a quarter vehicle model following Newton's second law.

$$
\begin{aligned}
m_{s} \ddot{z}_{s}= & -c_{0}\left(\dot{z}_{s}-\dot{z}_{u s}\right)-\left(k_{0}+k_{s}\right)\left(z_{s}-z_{u s}\right)-\alpha z_{B w}, \\
m_{u s} \ddot{z}_{u s}= & -c_{0}\left(\dot{z}_{u s}-\dot{z}_{u s}\right)-k_{u s}\left(z_{u s}-z_{r}\right) \\
& -\left(k_{0}+k_{s}\right)\left(z_{u s}-z_{s}\right)+\alpha z_{B w} .
\end{aligned}
$$

The last equations include an evolutionary variable related to the hysteresis of the MR damper, $z_{B w}$. This variable depends on the displacement history over time, as in equation (3) as reported in [41].

$$
\begin{aligned}
\dot{\mathrm{z}}_{\mathrm{Bw}}= & -\gamma\left|\dot{z}_{s}-\dot{z}_{u s}\right| z_{B w}\left|z_{B w}\right|^{n-1} \\
& -\beta\left(\dot{z}_{s}-\dot{z}_{u s}\right)\left|z_{B w}\right|^{n}+\delta\left(\dot{z}_{s}-\dot{z}_{u s}\right) .
\end{aligned}
$$

Furthermore, the dynamic behavior of the MR damper $\left(k_{0}, c_{0}\right.$, and $\left.\alpha\right)$ is equations (4)-(6). Moreover, there is a transient dynamic due to the internal MR damper characteristics. This behavior is modeled as a first-order system with a time constant $\eta=190 \mathrm{~s}^{-1}$.

A polynomial approach is used to fit the underlying parameters to nonlinear characteristics of the viscoelastic phenomena, as follows in equations (4)-(6), where $k_{a}, k_{b}, k_{c}$, $k_{d}, c_{a}, c_{b}, c_{c}, c_{d}, c_{e}, \alpha_{a}, \alpha_{b}, \alpha_{c}, \alpha_{d}$, and $\alpha_{e}$ are parameters to be determined according to the MR damper nonlinear characteristics where the current $i$ represents the control signal. It is important to mention that $k_{0}, c_{0}$, and $\alpha$ are dimensionless values. For more information on these variables, refer to $[38,42]$.

$$
\begin{aligned}
& k_{0}=k_{a}+k_{b} i+k_{c} i^{2}+k_{d} i^{3}, \\
& c_{0}=c_{a}+c_{b} i+c_{c} i^{2}+c_{d} i^{3}+c_{e} i^{4}, \\
& \alpha=\alpha_{a}+\alpha_{b} i+\alpha_{c} i^{2}+\alpha_{d} i^{3}+\alpha_{e} i^{4} .
\end{aligned}
$$

Equations (1)-(6) can be arranged in a state-space model. The state variables are listed as follows: sprung mass displacement $\left(x_{1}=z_{s}\right)$, sprung mass velocity $\left(x_{2}=\dot{z}_{s}\right)$, unsprung mass displacement $\left(x_{3}=z_{u s}\right)$, unsprung mass velocity $\left(x_{4}=\dot{z}_{u s}\right)$, and Bouc-Wen theoretical variable $\left(x_{5}=z_{B w}\right)$. Moreover, $w$ stands for the disturbance signal coming from the road profile. The state-space variables are organized as in the following equations:

$$
\begin{aligned}
& \dot{x}_{1}=x_{2}, \\
& \dot{x}_{2}=\frac{-\left(k_{s}+k_{0}\right)\left(x_{1}-x_{3}\right)-c_{0}\left(x_{2}-x_{4}\right)-\alpha x_{5}}{m_{s}} \\
& \dot{x}_{3}=x_{4}, \\
& \dot{x}_{4}=\frac{-\left(k_{s}+k_{0}\right)\left(x_{3}-x_{1}\right)-c_{0}\left(x_{4}-x_{2}\right)+\alpha x_{5}-k_{u s}\left(x_{3}-w\right)}{m_{u s}}, \\
& \dot{x}_{5}=-\gamma\left|x_{2}-x_{4}\right| x_{5}\left|x_{5}\right|-\beta\left(x_{2}-x_{4}\right)\left|x_{5}\right|^{2}+\delta\left(x_{2}-x_{4}\right) .
\end{aligned}
$$

To simplify the absolute value of a magnitude $\rho$, equation (12) is defined in which sign $(\rho)$ gives +1 if $\rho>0,-1$ if $\rho<0$, and 0 if $\rho=0$.

$$
\rho=|\rho| \operatorname{sign}(\rho) \text {. }
$$

Then, by replacing equation (12) in equation (11), it is possible to obtain equation (13). A reduction in the terms is done by using $M_{r}=-\gamma \operatorname{sign}\left(x_{2}-x_{4}\right) x_{5}\left|x_{5}\right|-\beta\left(x_{2}-\right.$ $\left.x_{4}\right)\left|x_{5}\right|^{2}$; then, equation (14) is obtained.

$$
\begin{aligned}
\dot{x}_{5}= & \left(x_{2}-x_{4}\right)\left(-\gamma \operatorname{sign}\left(x_{2}-x_{4}\right) x_{5}\left|x_{5}\right|-\beta\left|x_{5}\right| 2\right) \\
& +\delta\left(x_{2}-x_{4}\right), \\
\dot{x}_{5}= & \left(x_{2}-x_{4}\right) M_{r}+\delta\left(x_{2}-x_{4}\right) .
\end{aligned}
$$




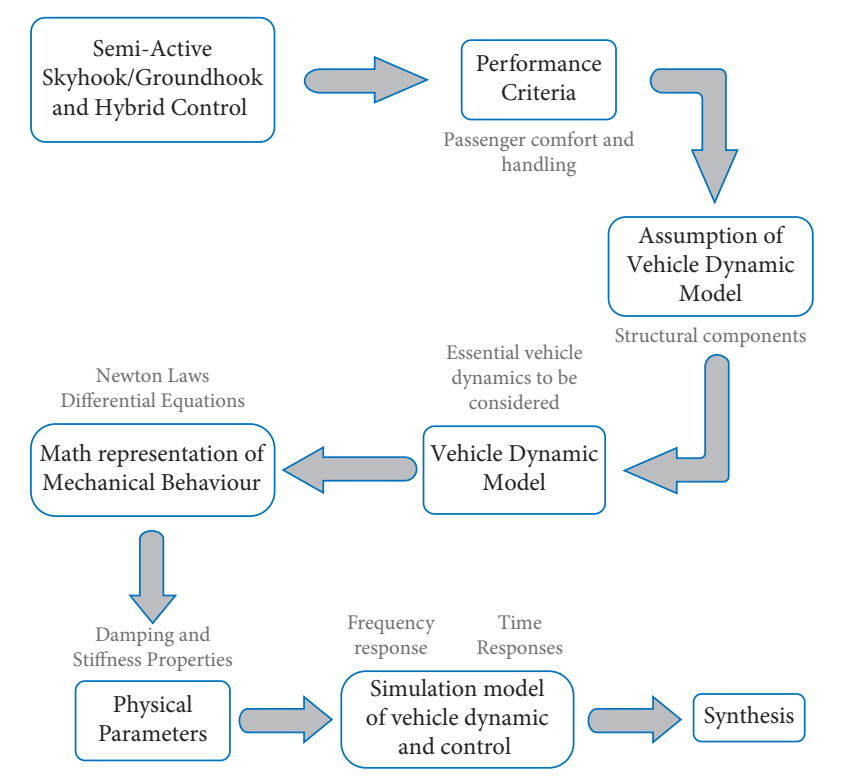

Figure 1: Methodology graphical representation.

From equations (7)-(13), a state-space model of the semiactive suspension system with a magnetorheological damper is represented in equations (15) and (16).

$$
\begin{aligned}
& \dot{x}=A x+B w, \\
& y=C x+D w .
\end{aligned}
$$

In equation (15), $\dot{x}$ is the state vector derivative, $A$ is the state matrix, $x$ is the state vector, $B$ is the input matrix related to the disturbance signal, and $w$ is the road profile signal. Moreover, in equation (16), $y$ is the output vector, $C$ is the output matrix, and $D$ is the direct transmissibility matrix due to disturbances. The state matrix $A \in R^{5 \times 5}$ depends on the number of state variables, and it is depicted in equation (17). Additionally, matrix $B$ is described in equation (18).

$$
\begin{aligned}
A & =\left[\begin{array}{ccccc}
0 & 1 & 0 & 0 & 0 \\
\frac{-\left(k_{s}+k_{0}\right)}{m_{s}} & \frac{-c_{0}}{m_{s}} & \frac{\left(k_{s}+k_{0}\right)}{m_{s}} & \frac{c_{0}}{m_{s}} & \frac{-\alpha}{m_{s}} \\
0 & 0 & 0 & 1 & 0 \\
\frac{\left(k_{s}+k_{0}\right)}{m_{u s}} & \frac{c_{0}}{m_{u s}} & \frac{-\left(k_{s}+k_{0}+k_{u s}\right)}{m_{u s}} & \frac{-c_{0}}{m_{u s}} & \frac{\alpha}{m_{u s}} \\
0 & \delta+M r & 0 & -(\delta+M r) & 0
\end{array}\right], \\
B & =\left[\begin{array}{lllll}
0 & 0 & 0 & \frac{k_{u s}}{m_{u s}} & 0
\end{array}\right]^{T} .
\end{aligned}
$$

The system's outputs are listed as follows: $y_{1}, y_{2}, y_{3}$, and $y_{4}$, which represent $z_{s}, \dot{z}_{s}, z_{u s}$, and $\dot{z}_{u s}$, respectively.

$$
\begin{aligned}
& y_{1}=x_{1}, \\
& y_{2}=x_{2}, \\
& y_{3}=x_{3}, \\
& y_{4}=y_{4}, \\
& y_{5}=\frac{\left(\left(k_{s}+k_{0}\right)\left(x_{3}-x_{1}\right)+c_{0}\left(x_{4}-x_{2}\right)-\alpha x_{5}\right)}{m_{u s}} .
\end{aligned}
$$

and $y_{5}$ represents the sprung mass acceleration.

From equations (21) and (22), the $C$ and $D$ matrices are defined as follows:

$$
C=\left[\begin{array}{ccccc}
1 & 0 & 0 & 0 & 0 \\
0 & 1 & 0 & 0 & 0 \\
0 & 0 & 1 & 0 & 0 \\
0 & 0 & 0 & 1 & 0 \\
\frac{-\left(k_{s}+k_{0}\right)}{m_{s}} & \frac{-c_{0}}{m_{s}} \frac{\left(k_{s}+k_{0}\right)}{m_{s}} & \frac{c_{0}}{m_{s}} & -\frac{\alpha}{m_{s}}
\end{array}\right],
$$

\section{Performance Criteria}

The main goals that the automotive suspensions must achieve are passenger comfort and vehicle stability. These goals need to be achieved simultaneously. Therefore, the benchmarks that are going to be done further herein consider those performance indices. A brief explanation of both indices is given below and is based on reported work [43-46].

The comfort index is the passenger's perception when traveling in the vehicle. Vibrations generated by the road profile go through the physical elements of the vehicle's suspension toward the passengers. Although the passenger perception is subjective and depends on each person, it is obligatory to come up with a standardized criterion to determine and measure passenger comfort [46]. Vehicle stability index is related to the suspension's ability to hold the tires in contact with the road profile even in the presence of surface irregularities [45]. To measure the degree of comfort and stability, this work will apply the following performance criteria:

(i) Ride comfort $(0-4 \mathrm{~Hz})$ at low frequencies: The objective is to reduce the resonance peak for the 


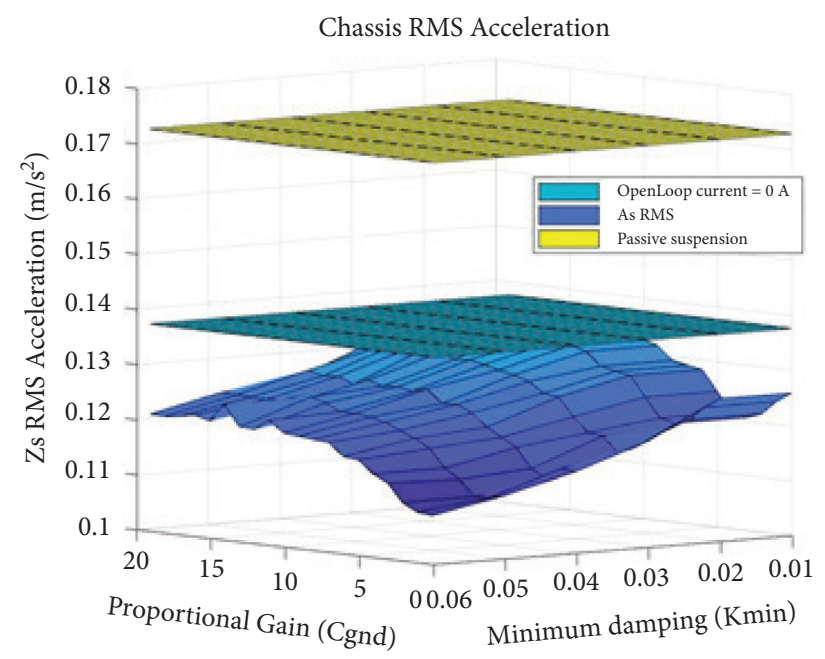

FIgURE 2: Decision control surface.

sprung mass which is around $1.1 \mathrm{~Hz}$ and also to reduce the relation between chassis displacement and road profile $\left(z_{s} / z_{r}<2\right)$. The disturbance is represented with a sinusoidal wave $\left(z_{r}=0.015 \mathrm{sin}\right.$ $(\omega t))$ with the amplitude in meters.

(ii) Ride comfort $(4-30 \mathrm{~Hz})$ at high frequencies: The goal is to reduce the chassis acceleration $\left(\ddot{z}_{S}\right)$ and keep the root mean square acceleration below $0.5 \mathrm{~m} /$ $\mathrm{s}^{2}$ as established in [45]. The disturbance signal must be a sinusoidal wave $\left(z_{r}=0.001 \sin (\omega t)\right)$ with the amplitude in meters.

(iii) Road holding $(0-15 \mathrm{~Hz})$ : The objective is to reduce the resonance peak for the unsprung mass which is around $10 \mathrm{~Hz}$ and to reduce the relation between tire displacement and road profile $\left(z_{u s} / z_{r}<2\right)$. The disturbance signal is the same as the one employed for ride comfort at high frequencies.

\section{Optimal Controller Design}

To determine the best performance, many controllers are implemented as a case of studies: skyhook controller, groundhook controller, and hybrid controller. This paper follows the design implemented in [40]; however, it could be used as any other kind of controller explained in the introduction.

5.1. Baseline Control Strategies. We improve these strategies to move toward an optimal approach to maximize certain performance criteria.

5.1.1. Skyhook Controller. This controller eliminates the problem in the passive suspension systems of the trade-off between resonance control and high frequencies [40]. This configuration consists of a semiactive damper connected to the sprung mass and a virtual sky frame. The main objective of the controller is to isolate the sprung mass from road disturbances. However, the effect has an opposite effect in the unsprung mass increasing its motion. The dynamic behavior is represented in equation (23). $F_{\text {sa }}$ represents the semiactive damper forces, $C_{\text {sky }}$ and $v_{\text {gnd }}$ represent the viscosity coefficient, $v_{1}$ represents the sprung mass velocity, $v_{2}$ represents the unsprung mass velocity, $v_{12}$ represents the differences between $v_{1}$ and $v_{2}$, and $k_{\min }$ represents the minimum forces the value could get.

$$
F_{\mathrm{sa}}= \begin{cases}C_{\mathrm{sky}} v_{1}, & v_{1} v_{12} \geq 0, \\ K_{\mathrm{min}}, & v_{1} v_{12}<0 .\end{cases}
$$

5.1.2. Groundhook Controller. The difference from the previous controller is that the damper is connected to the unsprung mass and the ground. This controller focuses on the unsprung mass isolating it from road disturbances. However, an increment in the motion of the sprung mass is obtained. The dynamics equations that rule the configuration are in equation (24). The variables are the same as the ones explained before.

$$
F_{\text {sa }}= \begin{cases}C_{\text {gnd }} v_{2}, & -v_{2} v_{12} \geq 0, \\ K_{\text {min }}, & -v_{2} v_{12}<0 .\end{cases}
$$

5.1.3. Hybrid Controller. The hybrid controller is an alternative controller when a trade-off between comfort and maneuverability wants to be achieved. This controller joints the benefits from the skyhook and the groundhook. Combining equations (23) and (24), it is possible to determine the semiactive hybrid controller logic represented in equations (25) to (27). Where new variables appear, $C_{\mathrm{hbd}}$ represents the controller's gain and $\alpha$ represents the proportion of each controller to be used. 


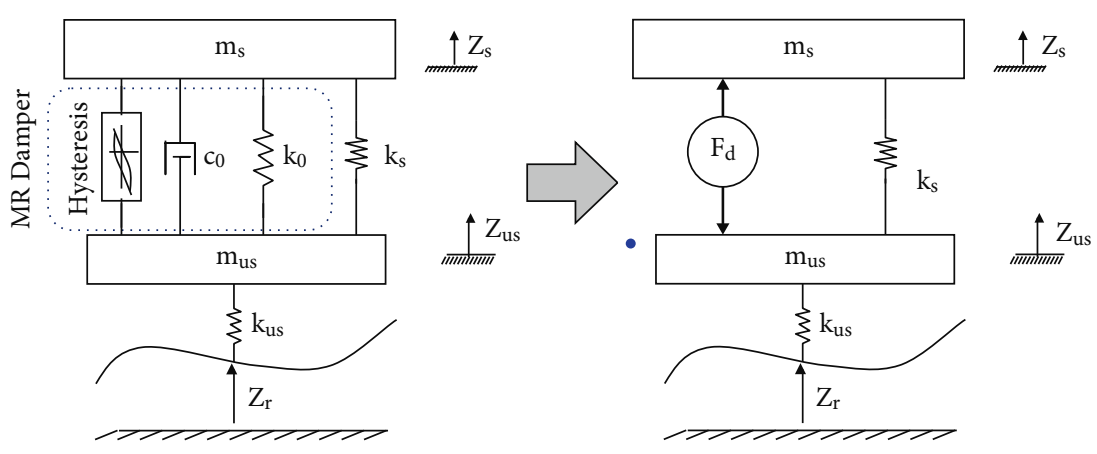

FIgURE 3: One-quarter vehicle with semiactive suspension.

$$
\begin{aligned}
& \sigma_{\text {sky }}= \begin{cases}C_{\text {sky }} v_{1}, & v_{1} v_{12} \geq 0, \\
K_{\text {min }}, & v_{1} v_{12}<0,\end{cases} \\
& \sigma_{\text {gnd }}= \begin{cases}C_{\text {gnd }} v_{2}, & -v_{2} v_{12} \geq 0, \\
K_{\text {min }}, & -v_{2} v_{12}<0,\end{cases} \\
& F_{\text {sa }}=C_{\text {hbd }}\left[\alpha \sigma_{\text {sky }}+(1-\alpha) \sigma_{\text {gnd }}\right] .
\end{aligned}
$$

The design of each controller was presented. In [40], it is explained that traditional damper forces depend on the velocity; thus, a linear approximation can be done where the damping constant is the rate change. However, this effect does not occur when an MR damper is used, and the graphics force-velocity is not linear but it is an envelope that is encompassed by an area. Then, the force is independent of the velocity and only depends on the current into the coil. Then, just for the controller design, equation (28) represents the ideal MR damper model where $i$ is the current sent by the controller and $C$ is a constant in a range $i=[0-1.75]$ A. Thus, when the simulation is made in Simulink $^{\mathrm{TM}}$, it is necessary to include a Current Limiter if the controller is oversaturated as proposed in [29]:

$$
F_{\text {MR-damper }}=C i \text {. }
$$

\subsection{Rationale That Supports the So-Called Optimal Decision} Surfaces. It is necessary to clarify the rationale behind the idea of using optimal decision surfaces. In the design of the controllers, we can understand that it is necessary to select the values that we will give to the controller parameters. In this way, in a heuristic way, the values are searched for the parameters that satisfy the performance indicators. However, when selecting the values in a heuristic way, we lose the notion of the behavior of the system for the whole range of values that the controller parameter can take.

Therefore, the implemented solution is to simulate the suspension response for each value that the parameters can take. These parameters vary within a certain range. In this way, we guarantee that we are fully aware of any performance index. Besides, we guarantee to be able to select the value for the control parameter that minimizes some performance index within the range.

On the other hand, the controllers explained in the previous section have two or more control parameters; consequently, the results will be shown in the forms of surfaces, where the independent variables are the control parameters, and the dependent variable is some performance index. From these surfaces, we can visualize for which combination of control parameters some performance index would be minimized. Therefore, the strategy is to vary the control parameters until the performance index is saturated. Consequently, we establish the working range for the parameters.

\section{Road Disturbances}

Different road surfaces are used to validate the performance of new controllers. Therefore, this section shows the mathematical approach to replicate these surfaces in Matlab $^{\mathrm{TM}}$. The surfaces are road profile ISO, road bump, and a sinusoidal function.

6.1. ISO Road Profile. This road is implemented accordingly to the designed one in [47] which follows the ISO 8608 Standard. Different road roughness profiles with different damage levels can be simulated. This report uses the road Class A-B:

$$
h(x)=\sum_{i=0}^{N} \sqrt{\Delta n} 2^{k} 10^{-3}\left(\frac{n_{0}}{i \Delta n}\right) \cos \left(2 \pi i \Delta n x+\varphi_{i}\right),
$$

where $x$ is the length of the road (m) from 0 to $L$; then, the points are equally spaced within an interval of $\Delta n=1 / L ; B$ is the sampling interval; then, the maximum theoretical sampling spatial frequency is $n_{\max }=1 / B$; the number of data points is represented by $N=n_{\max } / \Delta n=L / B ; n_{0}$ is spatial frequency defined by 0.1 cycles $/ \mathrm{m} ; \phi_{i}$ is the random phase angle with a uniform distribution from 0 to $2 \pi$ range; $k$ represents the ISO classification. The road profile is shown in Figure 4.

6.2. Road Bump. The road bump signal is a smooth wave, shown in Figure 5. This disturbance is not as much aggressive as a step function. The mathematical approach is shown in equation (30), where Amp represents the signals amplitude and it is equal to $0.015 \mathrm{~m}$, and the $\mathrm{w}=$ equal to $3.927 \mathrm{rad} / \mathrm{s}$. This surface is commonly used by automotive vehicle suspension's response tests when a disturbance is in the form of a pothole or road bump appears, as reported in [48]. 




FIGURE 4: Simulation scenery: road profile for A-B road ISO.

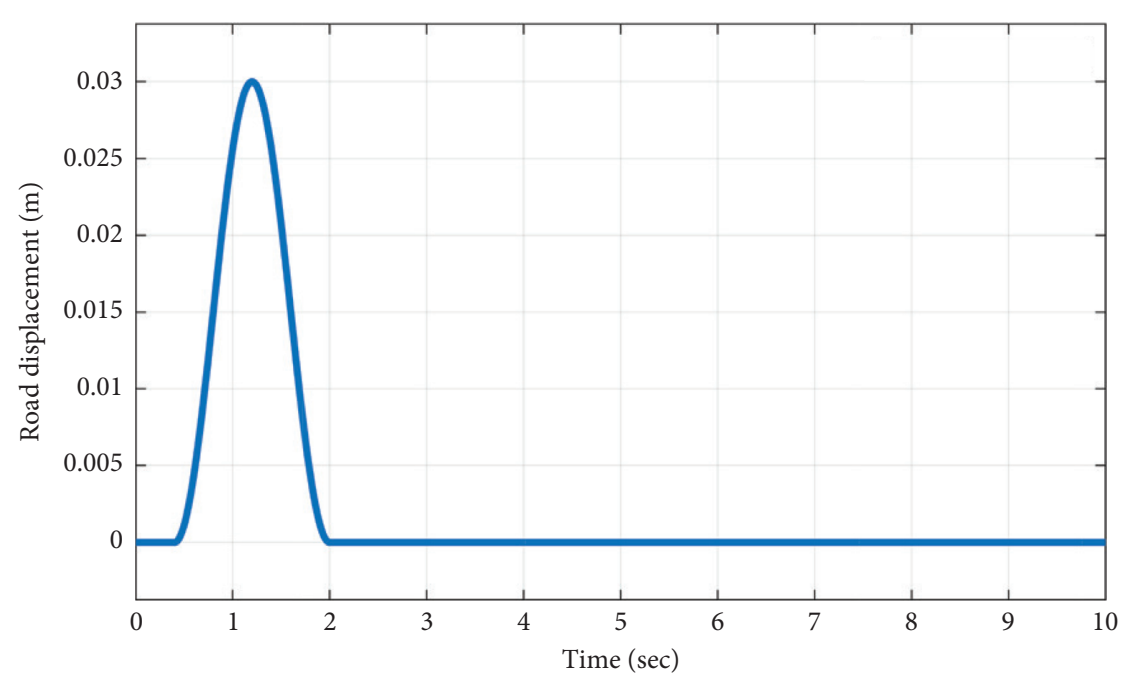

ROAD BUMP

Figure 5: Simulation scenery: road bump.

$z_{r}=\operatorname{Amp}(1-\cos (w t)) 0.4 \leq t \leq 2(s)$.

\section{Simulation and Results}

As was explained in the rationality, a graphical representation of the behavior of performance criteria is designed. The controllers presented before include two or more parameters that can be modified. Thus, the results are presented as multiple surfaces in which the independent axes represent the controller parameters, and the dependent axes represent the performance criteria. Analyzing these surfaces, it is possible to determine the most accurate behavior by choosing appropriate controller parameters. The graphics representation includes the responses of the passive suspension system and the open-loop system (not controller current applied). Both are represented by plane surfaces because the behavior does not depend on a controller parameter. Passive suspension and open-loop responses work as a restriction for the controller performance. Each combination of controller parameters that produce a response higher than the obtained one by the passive and open loop is not an accurate set of controller parameters and must not be chosen. Furthermore, a legend of every surface presented is included in the corner of each graphic.

The disturbances mentioned in Section 6 will be applied to the control systems to know the behavior of the vehicle. As seen in Section 5, the controllers depend on the variables $C_{\text {sky }}, C_{\text {gnd }}, C_{\mathrm{hbd}}$, and $K_{\text {min. }}$. Therefore, multiple simulations will be performed varying these variables uniformly. The performance criteria to be analyzed will be those mentioned in Section 4. These are the RMS values for chassis acceleration (As RMS) and suspension deflection. Besides, the result that would be obtained if a passive suspension is used 
will be added to each graph. These simulations will be carried out in Matlab $^{\mathrm{TM}} /$ Simulink $^{\mathrm{TM}}$ and will begin by presenting the skyhook controller and then the groundhook controller, and we will end with the hybrid controller.

The parameters of the one-quarter vehicle model are presented in Table 1, where $\delta$ is a dimensionless value, while the parameters of the MR damper are listed in Table 2. The one-quarter model parameters in Table 1 were chosen from [38]. Meanwhile, the MR damper parameters from Table 2 were taken from [39].

7.1. Test with Skyhook Controller. Figures 6-8 show the response of the controller when the road ISO is the input. The variable $C_{\text {sky }}$ varies from 0 to 20 while the variable $K_{\min }$ goes from 0 to 0.06 . The chassis acceleration RMS response shows that the controller has an improvement for every kind of variable configuration. Furthermore, the responses of the controller keep a reduction of $41 \%$ with a $C_{\text {sky }}$ higher than 5 . The suspension displacement has the same behavior and reduces $50 \%$ of the response when $C_{\text {sky }}$ is higher than 6 . Also, the wheel deformation has an improvement of $33 \%$ when $C_{\text {sky }}$ is higher than 8 .

Figures 9-11 show the response of the controller when the road bump is the input. The range is the same for all the variables. The chassis acceleration shows an improvement for all variables combined with a reduction of $30 \%$ compared with the passive suspension response. The response of the controller for the suspension displacement shows lower values when the minimum damping increases and is higher than 0.03 with a maximum reduction of $62.5 \%$ compared with the passive suspension. The wheel deformation RMS shows a reduction of $30 \%$ for all kinds of configurations compared with the passive suspension system.

As a finding, it can be observed that the main objective of reducing the chassis acceleration is accomplished when both types of disturbance signals are applied.

7.2. Test with Groundhook Controller. Figures 12-14 show the response of the controller when the road ISO is the input. The variable $C_{\text {gnd }}$ varies from 0 to 20 while the variable $K_{\min }$ goes from 0 to 0.06 . The chassis acceleration RMS response, Figure 12, of the controller shows an increment of $16 \%$ compared with the passive suspension system when $C_{\text {gnd }}$ is equal to 6; for the rest of the combinations of the values, the increment goes higher. The suspension displacement RMS response, Figure 13, of the controller shows a reduction of $33 \%$ compared with the passive suspension when the $C_{\text {gnd }}$ variable is higher than 10 . However, when lower values than 5 are chosen for this variable, the response of the controller gets worse with an increment of $50 \%$ compared with the passive suspension. The wheel deformation RMS, Figure 14, shows a reduction of $16 \%$ compared with the passive suspension response when the $C_{\text {gnd }}$ variable is higher than 5 and this relation keeps equals for the rest of the combinations of the values.

Figures 15-17 show the response of the controller when the road bump is the input. The range is the same for all the variables. The acceleration RMS response of the controller, Figure 15, shows a minimum reduction of $23 \%$ compared with the passive suspension when lower values of the minimum damping are chosen. The suspension displacement RMS, Figure 16, shows a reduction of 57\% compared with the passive suspension for all variable value combinations. Furthermore, the wheel deformation response, Figure 17 , shows a reduction of $25 \%$ compared with the passive suspension response, and also a better performance is obtained when the minimum damping is higher than 0.5 .

The identified finding is compliance in the road holding criterion for both disturbance inputs.

7.3. Test with Hybrid Controller. For all the tests with this controller, the independent variables are $C_{\text {sky }}, C_{\text {gnd }}$, and $\alpha_{\text {hybrid. }}$. The variables $C_{\text {sky }}$ and $C_{\text {gnd }}$ go from 0 to 20 while $\alpha_{\text {hybrid }}$ goes from 0 to 1 . When $\alpha_{\text {hybrid }}$ is equal to 1 , a skyhook controller is obtained while when it is 0 , a groundhook controller is obtained. Also, from equation (27), the variable $C_{\mathrm{hbd}}$ that represents the hybrid controller gain is set to 1 in all the simulations. Furthermore, the passive suspension system response and the open loop controller are shown in all the graphics with colors yellow and red, respectively.

Figures 18-20 show the response of the hybrid controller when the road ISO is the input. As was expected when the hybrid controller works more likely than a skyhook controller, a reduction compared with the passive suspension is obtained. However, there is a specific range when the hybrid controller has lower values than the passive suspension and $\alpha_{\text {hybrid }}$ goes from 0.2 to 0.8 . This range is inside the next boundary $C_{\text {sky }}>4$ and $C_{\text {gnd }}<10$.

The suspension displacement RMS, Figure 19, has a maximum reduction of $50 \%$ compared with the passive suspension. The boundary of this results is for all values of $\alpha_{\text {hybrid }}$ higher than 0.2 , lower than 0.8 , and any kind of $C_{\text {sky }}$ and $C_{\text {gnd }}$ configuration. The wheel deformation graphics show that using $\alpha_{\text {hybrid }}$ between 0.2 and 0.8 we can get a better reduction compared with the skyhook controller and even with the groundhook controller. However, when this range of $\alpha_{\text {hybrid }}$ is used, it is not necessary to choose a specific value for $C_{\text {sky }}$ and $C_{\text {gnd. }}$. The reduction is about $11 \%$ compared with the passive suspension response.

Figures 21-23 show the response of the controller when the road bump is the input. The range is the same for all the variables. The acceleration RMS is practically the same for every kind of configuration except for an open-loop configuration. Also, a reduction of $28 \%$ is achieved compared with a passive suspension system.

The suspension displacement decreases $80 \%$ in comparison with a passive suspension, when $\alpha_{\text {hybrid }}$ goes from 0.2 to 0.8 and the variables $C_{\text {sky }}$ and $C_{\text {gnd }}$ are higher than 15 . Otherwise, groundhook and skyhook controllers show the same performance decreasing the responses by 50\%. Figure 23 shows the wheel deformation of the model. Nevertheless, the responses of all the configurations practically give the same results reducing the deformation by around $30 \%$ except for the open-loop configuration.

7.4. Frequency Domain Tests. For this test, the input signals were presented in Section 4. The results are shown as 
TABLE 1: One-quarter model parameters.

\begin{tabular}{lcc}
\hline Symbol & Parameter & Value \\
\hline$m_{s}$ & Sprung mass & $400 \mathrm{~kg}$ \\
$m_{u s}$ & Unsprung mass & $40 \mathrm{~kg}$ \\
$k_{s}$ & Spring constant & $20,000 \mathrm{~N} / \mathrm{m}$ \\
$k_{u s}$ & Rim hardness & $210,000 \mathrm{~N} / \mathrm{m}$ \\
$\beta$ & Dynamic behavior of the MR damper & $1.2 * 10^{6} \mathrm{~m}^{-2}$ \\
$\gamma$ & Dynamic behavior of the MR damper & $1 * 10^{6} \mathrm{~m}^{-2}$ \\
$\delta$ & Dynamic behavior of the MR damper & 15 \\
$x_{i}$ & Initial state values & 0 \\
\hline
\end{tabular}

TABLE 2: MR damper parameters.

\begin{tabular}{lc}
\hline & Value $(\mathrm{Ns} / \mathrm{m})$ \\
\hline$c_{a}$ & 320.6 \\
$c_{b}$ & 1179.6 \\
$c_{c}$ & -1681.4 \\
$c_{d}$ & 1080.6 \\
$c_{e}$ & -242.6 \\
\hline & Value $(\mathrm{N} / \mathrm{m})$ \\
\hline$\alpha_{a}$ & 14060 \\
$\alpha_{b}$ & 236610 \\
$\alpha_{c}$ & -338620 \\
$\alpha_{d}$ & 218780 \\
$\alpha_{e}$ & -49470 \\
$k_{a}$ & 605,894 \\
$k_{b}$ & $-235,805$ \\
$k_{c}$ & $-63,261$ \\
$k_{d}$ & 37,495 \\
\hline
\end{tabular}

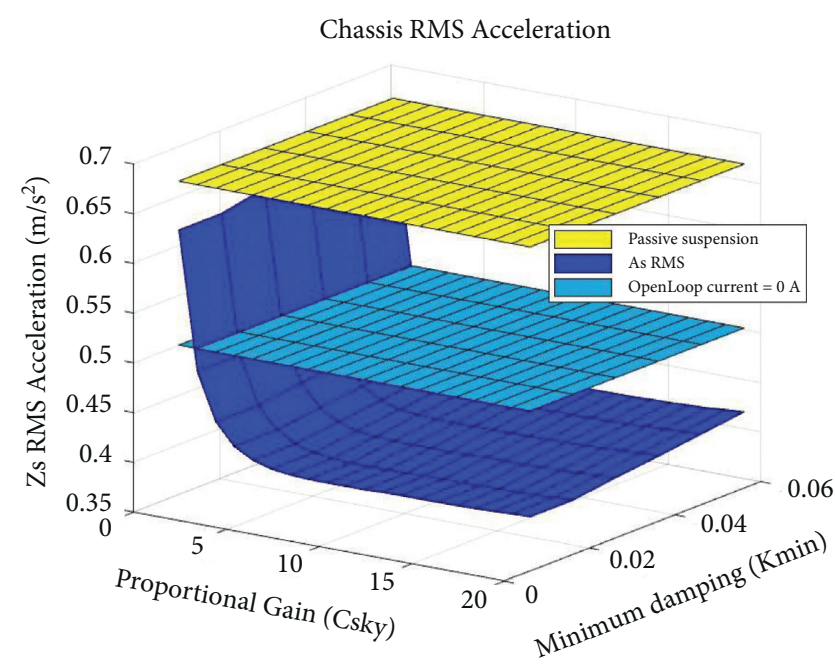

FIGURE 6: Chassis rms acceleration with a skyhook controller, and a road ISO profile.

descriptive functions (PseudoBode plots) [49]. Figures 24-27 show the vehicle behavior when different sinusoidal input signals with different frequencies are applied. The graphics show a comparison between multiple controllers: skyhook, groundhook, hybrid, open loop, and passive quarter vehicle.

Based on the surfaces presented before, a selection of the variable values was made to obtain the best performance. For the skyhook controller, the gain was set to 6 and the minimum damping to 0.01 . For the groundhook controller, the gain was set to 6 and the minimum damping to 0.01 . For the hybrid controller, the skyhook gain was set to 6 ; the groundhook was increased to 6 ; the hybrid gain was established to 1 , and the minimum damping, to 0,01 .

In Figure 24, the passive suspension response fails to accomplish the maximum gain requirement for $\left(z_{s} / z_{r}\right)$ of 2 . Meanwhile, in all the frequency range (especially at $1 \mathrm{~Hz}$ ), the rest of the controllers accomplish the requirement of keeping the gain below 2 . However, the open-loop system showed a worse performance compared with the passive suspension. The same results are shown in Figure 25 where the controllers show attenuation of the magnitude at low frequencies compared with the passive suspension and open loop. In Figure 26, all the controllers fail to accomplish the maximum gain requirement for $\left(z_{u s} / z_{r}\right)$ less than two at high frequencies.

A summary of the transmissibility responses is presented in Table 3. This table presents the sprung mass transmissibility $\left(z_{s} / z_{r}\right)$ in one row and the unsprung mass transmissibility $\left(z_{u s} / z_{r}\right)$ in the second row. Furthermore, the responses analyzed are from the passive suspension, the open-loop system, the skyhook controller, groundhook controller, and hybrid controller. The gain values for the sprung mass transmissibility are chosen when the frequency is around $1 \mathrm{~Hz}$ while that for the unsprung mass is around $10 \mathrm{~Hz}$.

The simulation conditions (suspension parameters, disturbance signals, outputs of interest, simulation time, among others) are the same for both passive and semiactive suspensions. Table 3, which is the summary of the comparisons, shows the maximum transmissibility and acceleration values in the resonance peaks. Furthermore, the performance criteria, described in Section 4, were applied in the same way for both suspensions.

The frequency response of the passive suspension and open loop do not accomplish the performance criteria for the sprung mass nor the unsprung muss. The skyhook sprung mass transmissibility accomplishes the performance criteria and reduces the response by $53 \%$ compared with a passive suspension; however, the unsprung mass transmissibility increases and it is higher than the presented one by the passive suspension.

This result works accordingly to what was expected because the purpose of the skyhook controller is to increase comfort while the maneuverability is reduced. The responses of the groundhook and hybrid controller are practically the same for the sprung mass and unsprung mass 


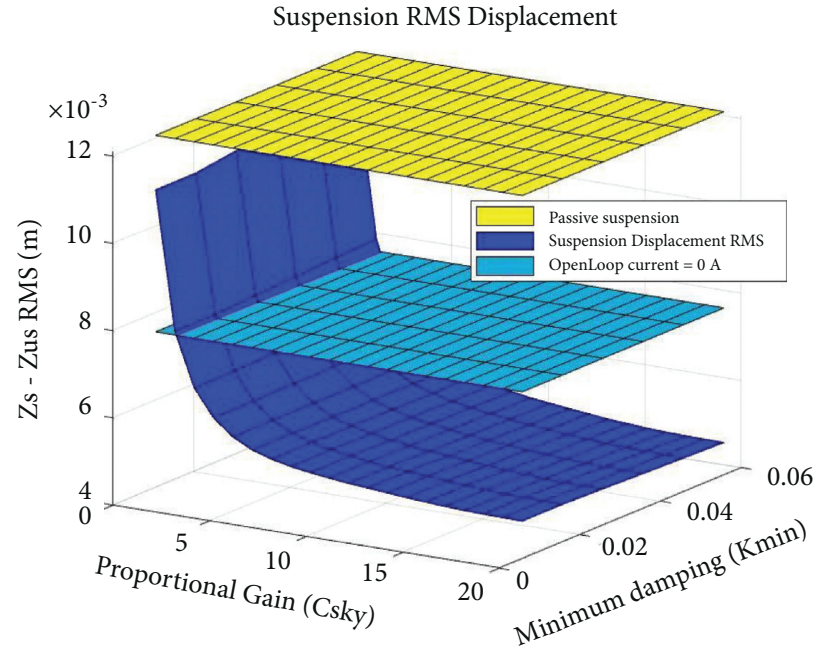

FIGURE 7: Suspension rms displacement with a skyhook controller, and a road ISO profile.

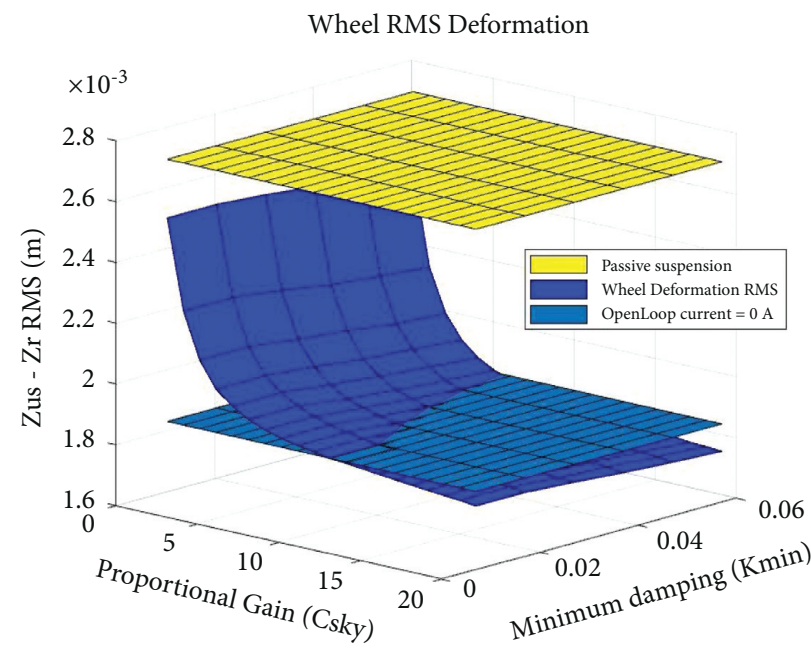

FIgURE 8: Wheel rms deformation with a skyhook controller, and a road ISO profile.

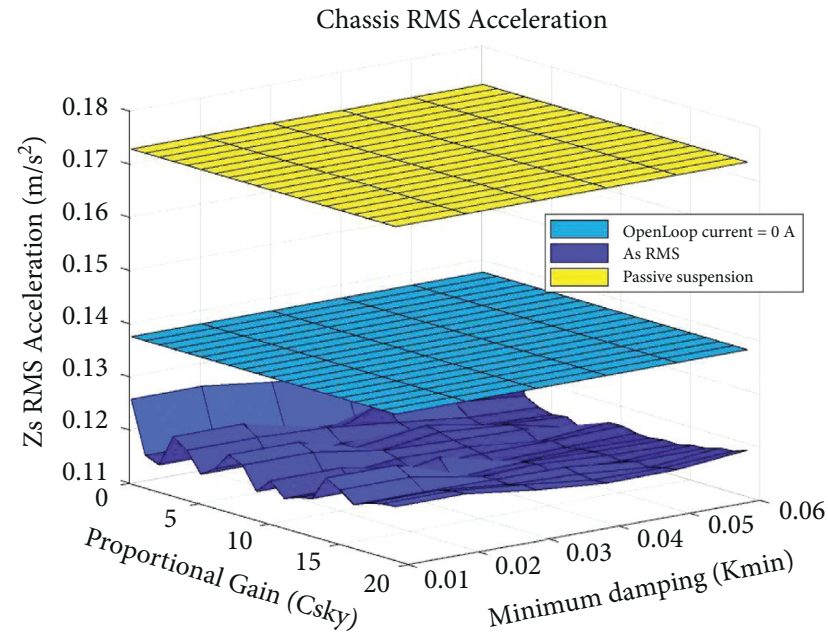

Figure 9: Chassis rms acceleration with a skyhook controller, and a road bump profile. 


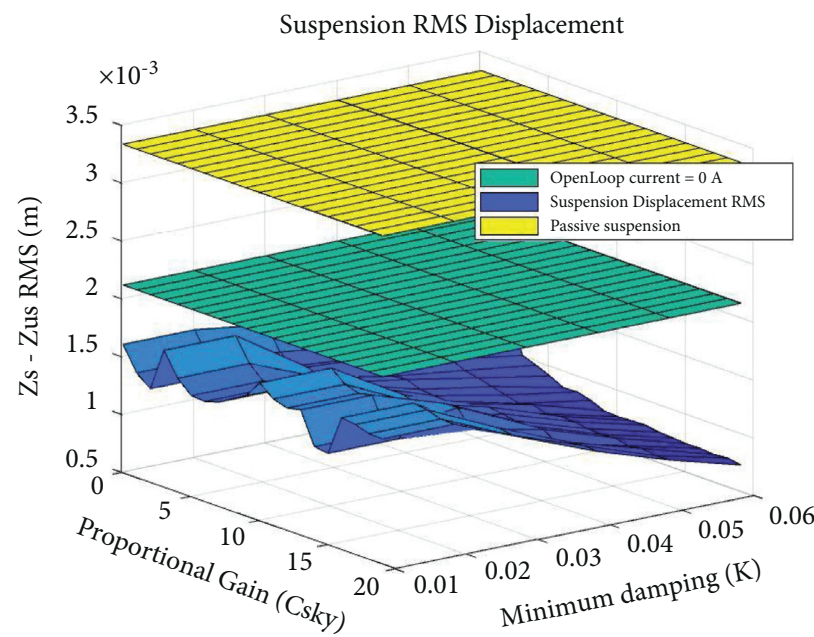

Figure 10: Suspension rms displacement with a skyhook controller, and a road bump profile.

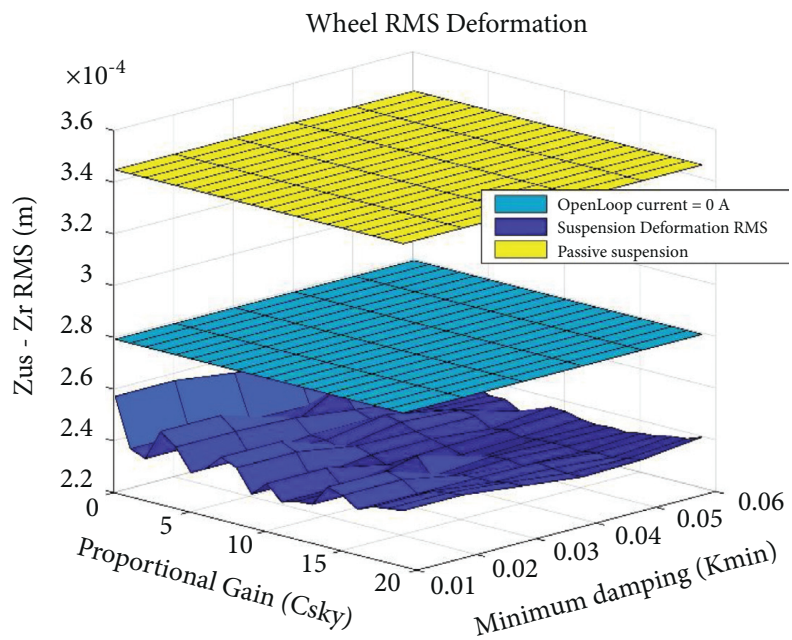

FIGURE 11: Wheel rms deformation with a skyhook controller, and a road bump profile.

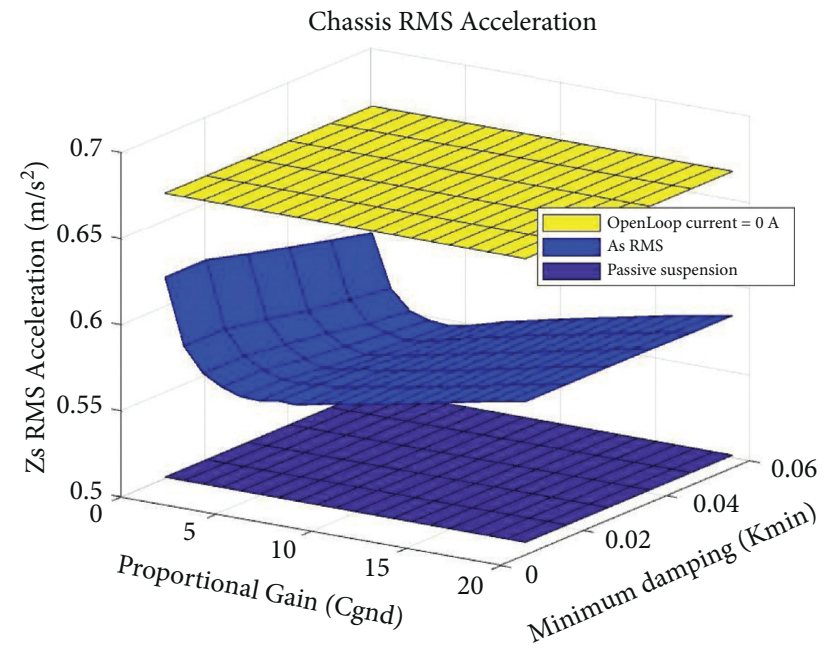

FIGURE 12: Chassis rms acceleration with a groundhook controller, and a road ISO profile. 


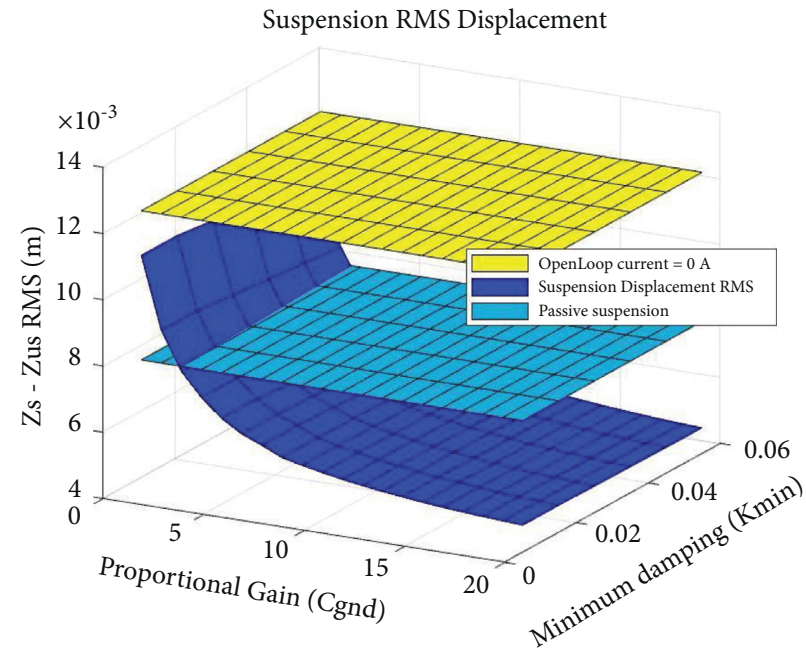

FIGURE 13: Suspension rms displacement with a groundhook controller, and a road ISO profile.

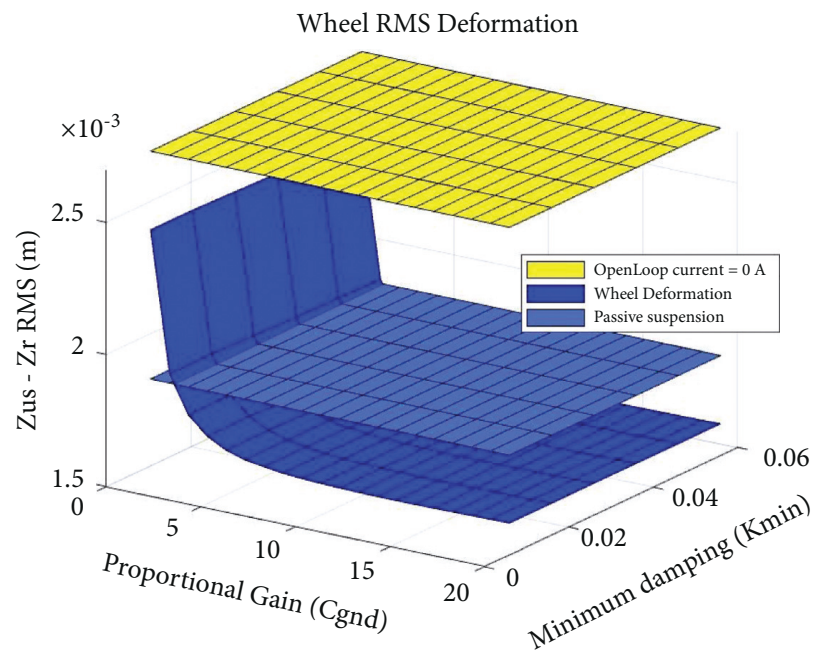

FIGURE 14: Wheel rms deformation with a groundhook controller, and a road ISO profile.

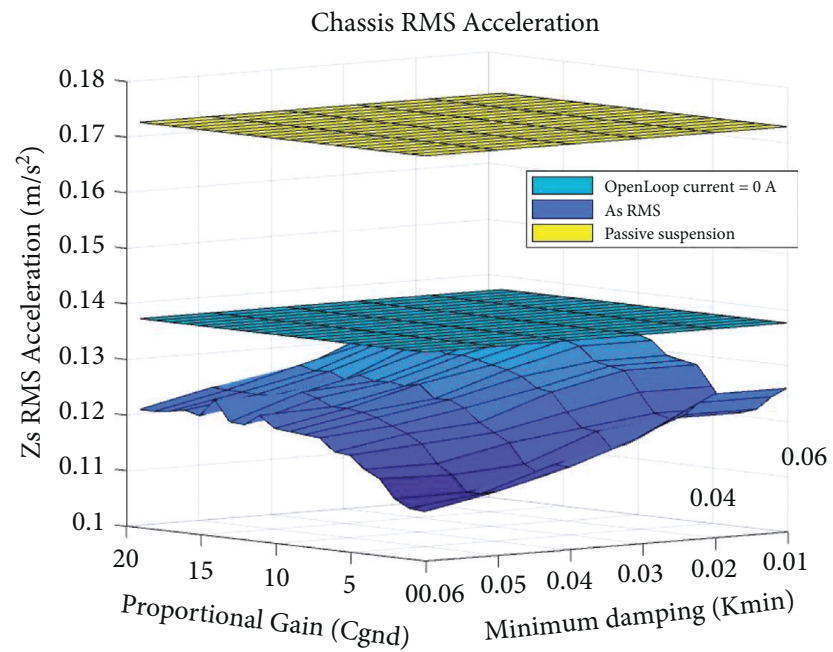

FIGURE 15: Chassis rms acceleration with a groundhook controller, and a road bump profile. 


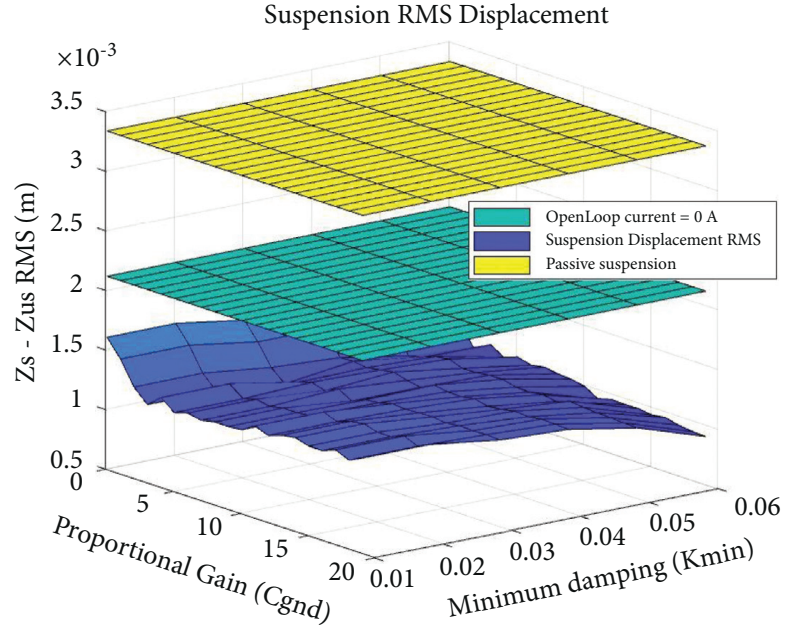

Figure 16: Suspension rms displacement with a groundhook controller, and a road bump profile.

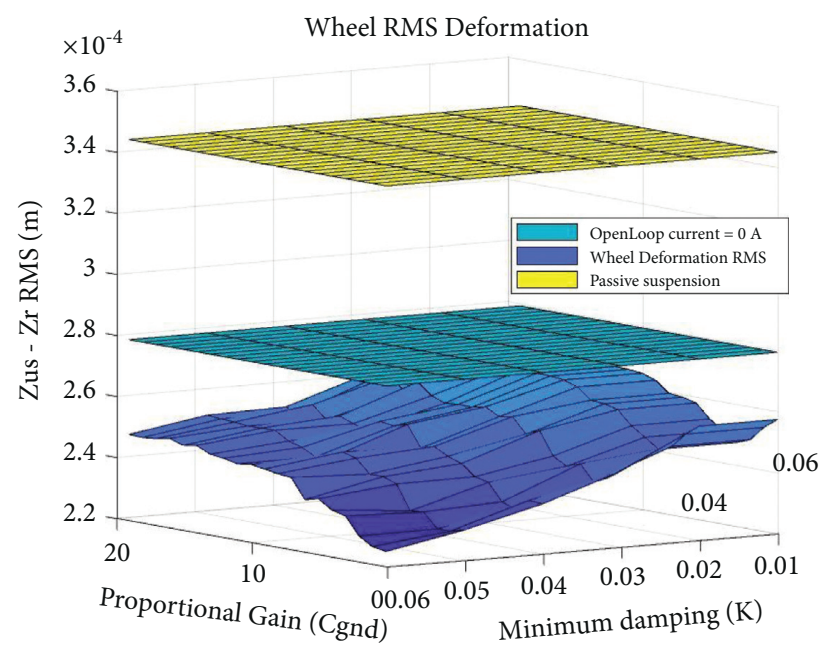

FIgURE 17: Wheel rms deformation with a groundhook controller, and a road bump profile.

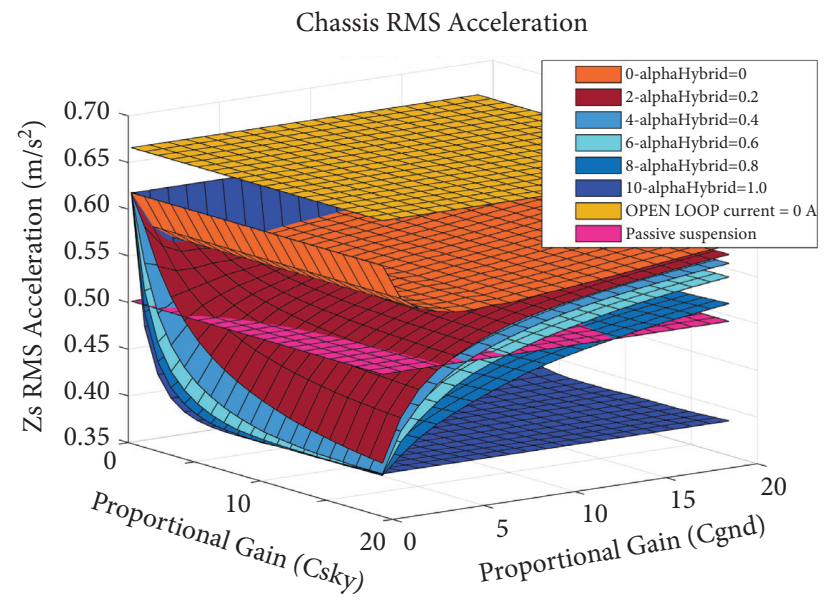

FIGURE 18: Chassis rms acceleration with a hybrid controller, and a road ISO profile. 


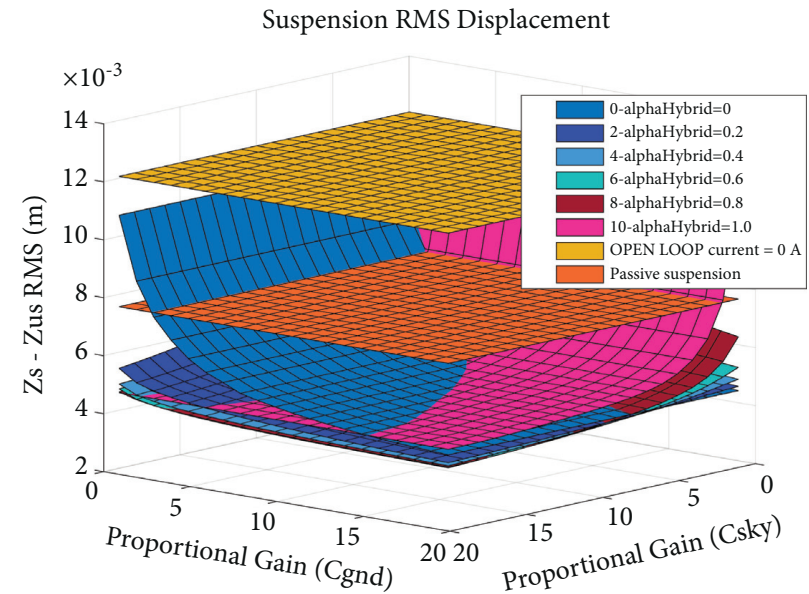

FIGURE 19: Suspension rms displacement with a hybrid controller, and a road ISO profile.

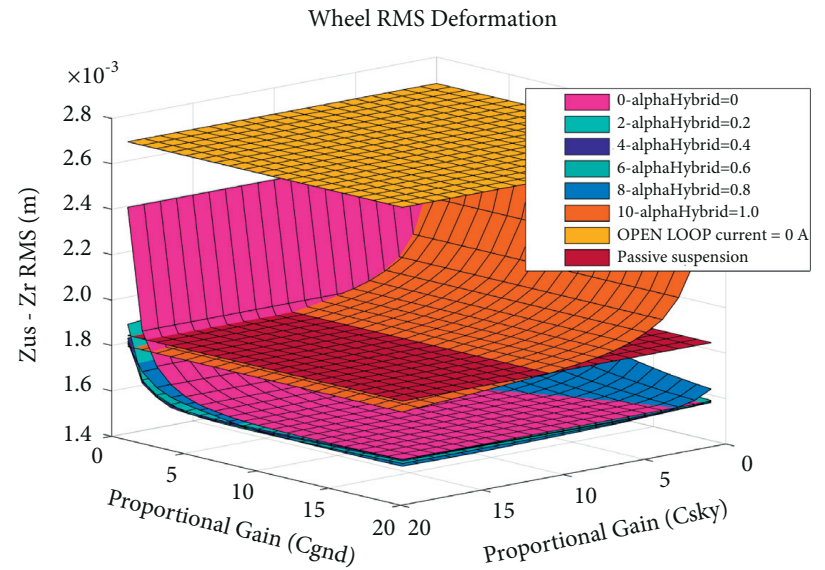

Figure 20: Wheel rms deformation with a hybrid controller, and a road ISO profile.

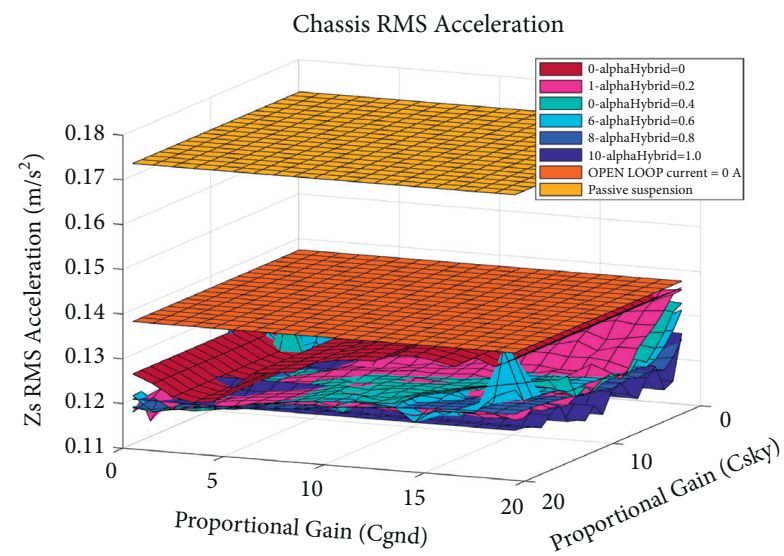

FIgURE 21: Chassis rms acceleration with a hybrid controller, and a road bump profile. 


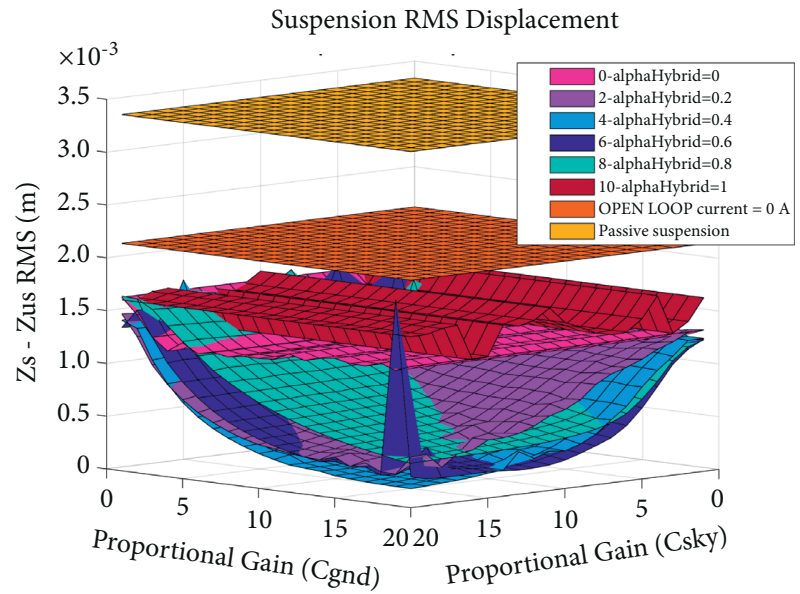

FIgURE 22: Suspension rms displacement with a hybrid controller, and a road bump profile.

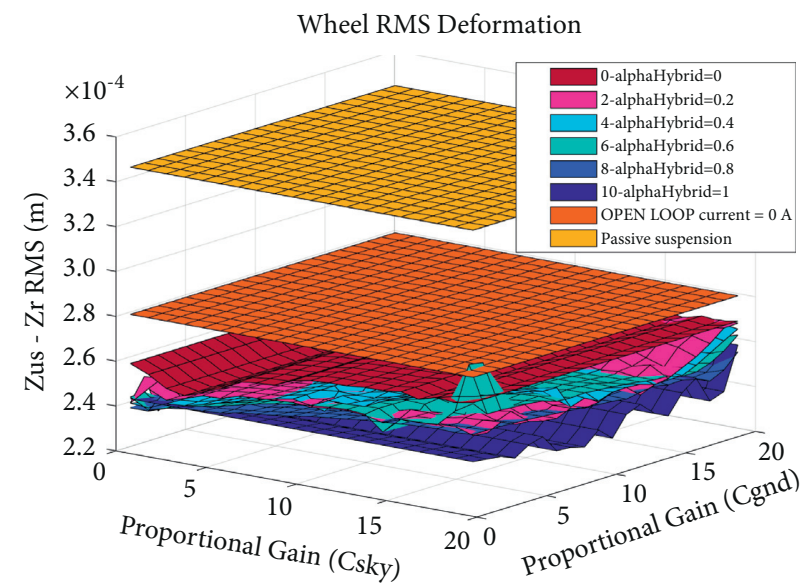

FIgURE 23: Wheel rms deformation with a hybrid controller, and a road bump profile.

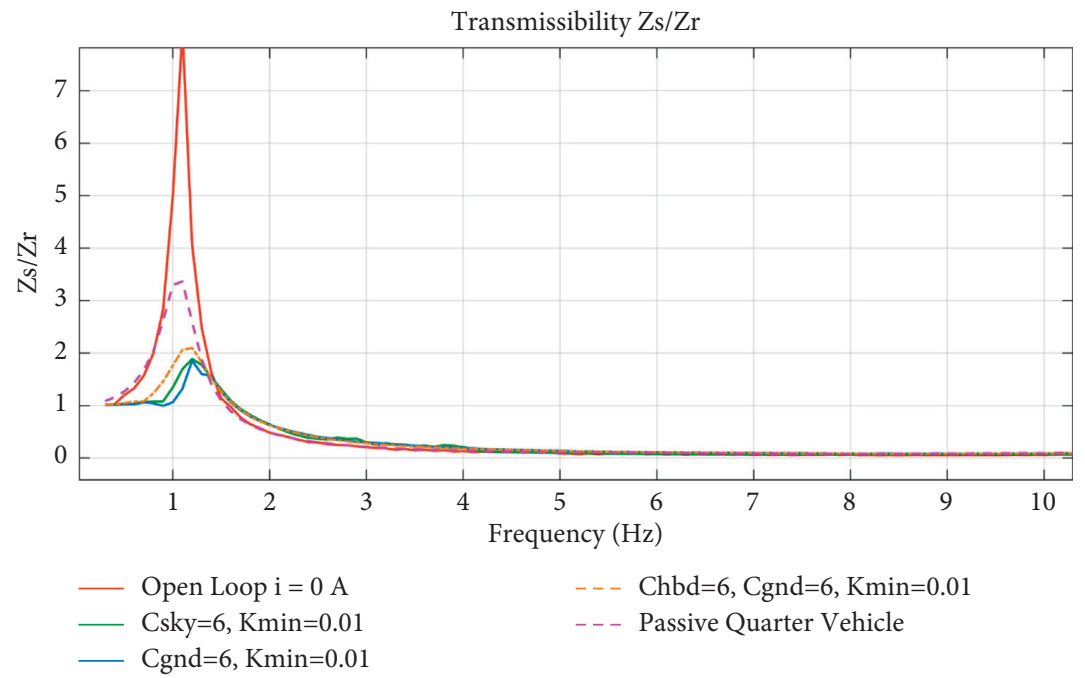

Figure 24: Ratio between the chassis displacement and the road disturbance. 


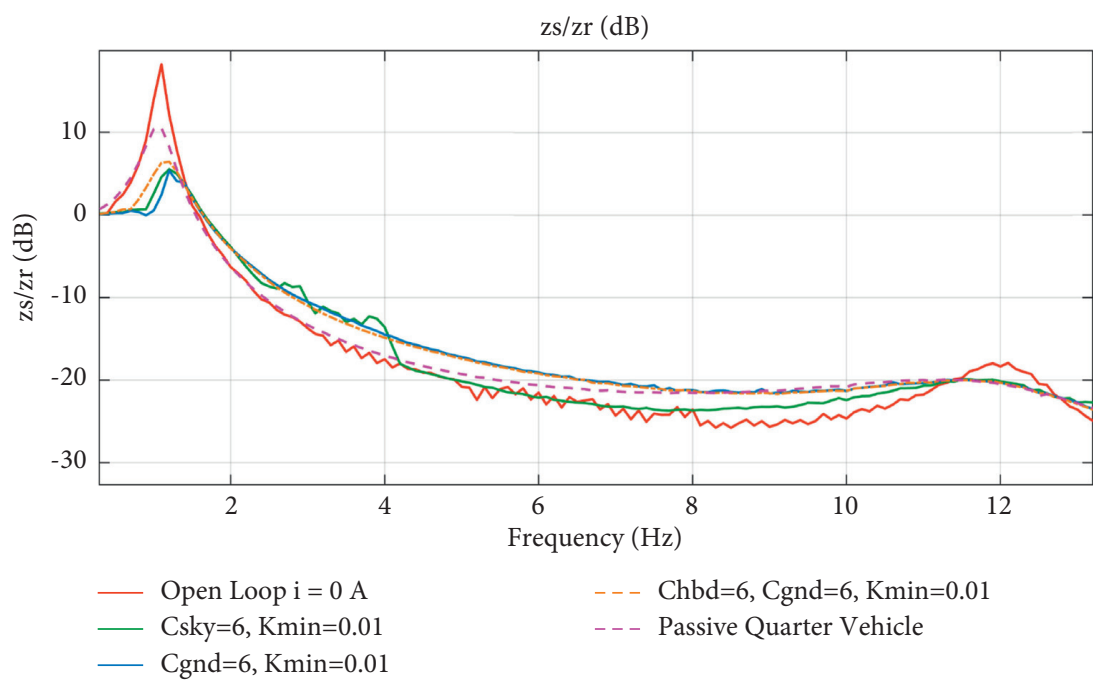

Figure 25: Pseudobode chassis displacement.

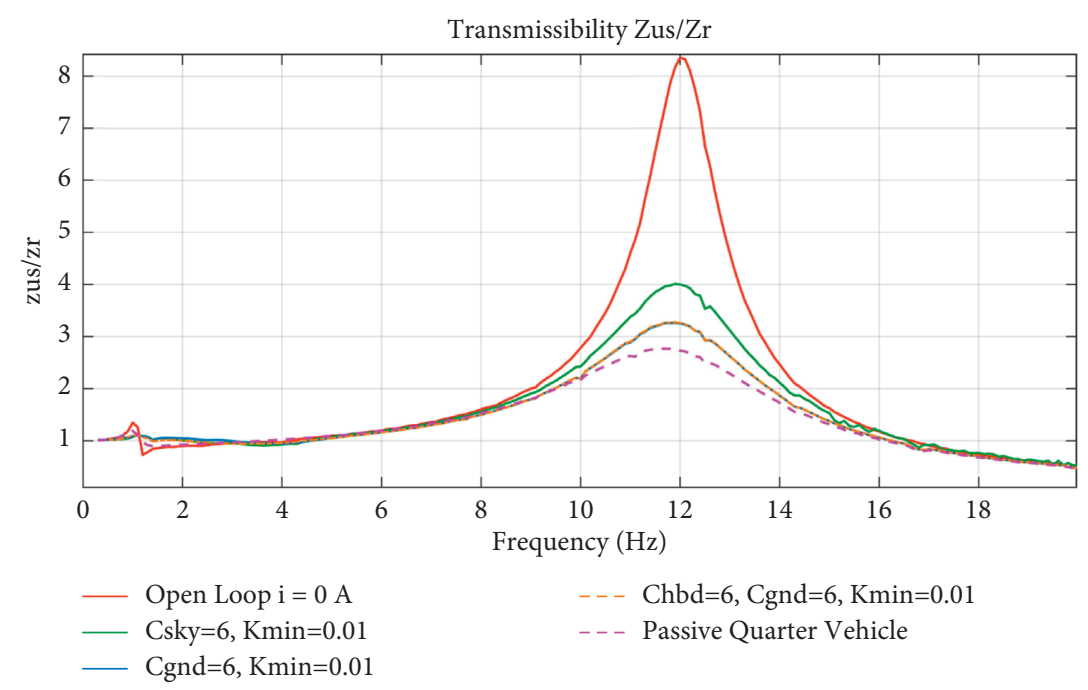

FIgURE 26: Ratio between the unsprung mass displacement and the road disturbance.

transmissibility. Both accomplish the performance criteria for the sprung mass and reduce by $48 \%$ compared with a passive suspension. However, this controller does not accomplish the unsprung mass transmissibility requirements. These results could be better than the response obtained by the passive suspension if more accurate controller variables are selected based on the decision surfaces from Figures 12 to 18.

To have a better understanding of the methodology achievement, the results are compared with reported works. This research compares the results with those presented in [36] (A) and [37] (B) because they have some important analogies, for example, the mathematical model to represent the one-quarter vehicle with a semiactive suspension and the application of skyhook, groundhook, and hybrid controllers. Although the numerical values of suspension and MR damper are not the same, results in A, B, and herein contrast the passive suspension performance with the proposed ones and report a percentage of improvement for some common performance criteria. The comparison with the passive suspension could give a better dimensioning of the herein obtained improvements. The summary of outcomes is presented in Table 4.

For $\left(z_{s} / z_{r}\right)$, the percentage of improvement is pretty much similar to the presented ones in A and B. There is an improvement of $10 \%$ with respect to the presented one in $A$, but not if it is compared with B. For $\left(z_{u s} / z_{r}\right)$, the result of each work shows that all suspension models have a similar performance and there is not a relevant improvement. For $\left(z_{s}-z_{u s}\right)$, the proposed methodology reduces, on average, $50 \%$ of the suspension displacement compared with a passive suspension system. Furthermore, these results are higher than the presented in the skyhook methodology presented in A; meanwhile, B does not include these results. 


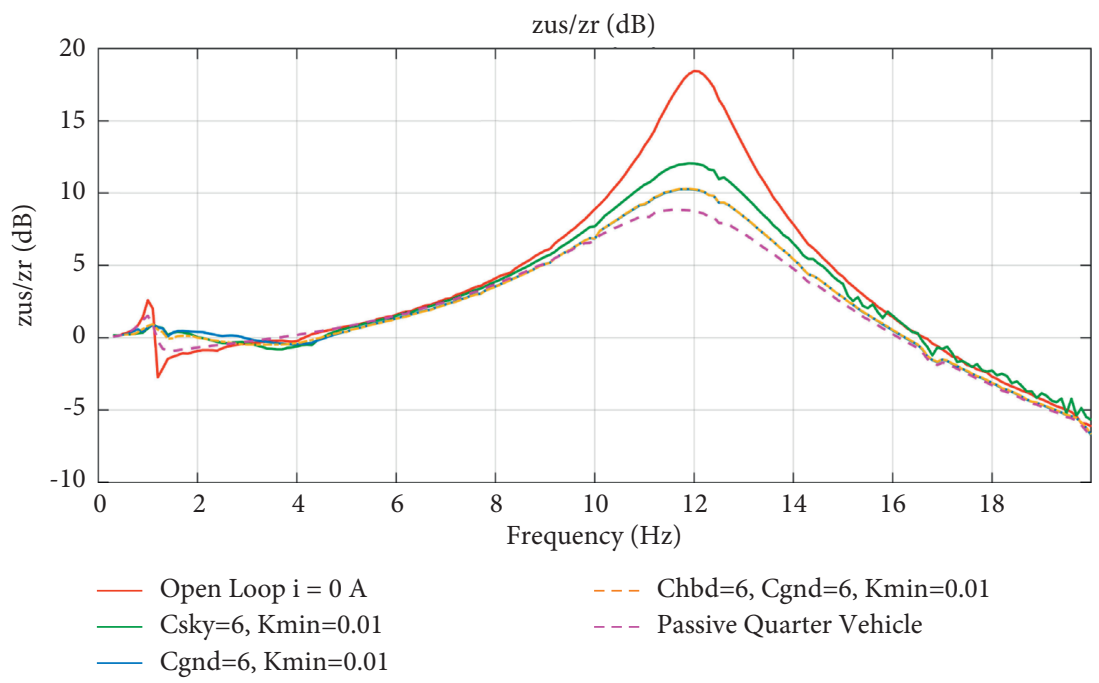

Figure 27: Pseudobode unsprung mass displacement.

TABLE 3: Summary of frequencies responses results from Figures 24-27.

\begin{tabular}{lccccc}
\hline Suspension & Passive & Open loop & Skyhook & Groundhook & Hybrid \\
\hline$z_{s} / z_{r}$ gain & 3.4 & 4.2 & 1.6 & 1.7 & 1.8 \\
$z_{u s} / z_{r}$ gain & 2.8 & 8.4 & 4 & 3.2 & 3.2 \\
\hline
\end{tabular}

TABLE 4: Comparison of reported works with proposed work and passive suspension.

\begin{tabular}{|c|c|c|c|c|}
\hline$\%$ improvement & Skyhook (2019) [36] & Groundhook (2019) [36] & Hybrid (2017) [37] & Control surfaces \\
\hline$\left(z_{s} / z_{r}\right)$ & $50 \%$ & $55 \%$ & $70 \%$ & $60 \%$ \\
\hline$\left(z_{u s} / z_{r}\right)$ & \multicolumn{2}{|c|}{ Minor $(\leq 2 \%)$} & Not improved & Not improved \\
\hline$\left(z_{s}-z_{u s}\right)$ & $40 \%$ & $80 \%$ & Not reported & $50 \%$ \\
\hline$\left(\ddot{z}_{s}\right)$ & $8 \%$ & $10 \%$ & $40 \%$ & $30 \%$ \\
\hline
\end{tabular}

For the chassis acceleration $\left(\ddot{z}_{s}\right)$, a considerable $20 \%$ of improvement is obtained compared with A but $10 \%$ worse than the presented in $\mathrm{B}$.

\section{Conclusions and Further Work}

The proposed methodology allows obtaining the controller parameters that accomplish specific performance criteria. Furthermore, it can work as a pathway for suspension systems designers who want to get comfortable and stable solutions. Moreover, the herein methodology is not limited to a specific controller structure, and it can be applied with other controllers or suspension systems.

The generated surfaces allow you to select the controller's constants. They provide relevant information about the behavior of the performance criteria when the controller's parameters vary. This offline tuning approach contributes to determining the controller's parameters combination that most reduces/increases performance criteria. Then, a kind of optimal controller is selected with the appropriate parameter values.

Following this methodology, an improvement was obtained versus a passive suspension. For the developed case study and selecting appropriate controller parameters, the measured performance criterion was optimized within the considered simulation conditions. However, it is noticed that each controller has its distinctive advantage; e.g., the skyhook controller works better, reducing the sprung mass acceleration but increasing the tire displacement. Meanwhile, the groundhook controller increases the maneuverability but reduces passenger comfort (by increasing the sprung mass acceleration). Furthermore, the hybrid controller, after the proposed tuning approach, can meet road holding and passenger comfort criteria simultaneously.

To reinforce the validation and limitations of this research, a strategic comparison with reported results was performed. This task also provides a broader idea about the improvements of the proposed methodology when it is compared against similar reported results The results obtained in this research compete with those already reported as in $[36,37]$ although some opportunity areas could be addressed. Moreover, the compared results show that the methodology is viable and can be improved for its use in suspension design.

One line of research is the study of the robustness of the system when modifying some parameters of the suspension. 
It would be worth applying the optimal surfaces approach to more complex suspension models such as half vehicle and full vehicle. With these models, interesting dynamics, such as pitch, roll, and yaw, could be studied to extend the scope of suspension evaluation beyond vertical dynamics. It would be interesting to see a real suspension behavior under the signals applied to the controller. For this reason, the researchers would keep improving on the experiments and would implement Hardware-in-the-Loop tests in further works. Multiple approaches could be developed such as the ones proposed in [50] and [51] where Hardware-in-theLoop and Software-in-the-Lop are integrated. Also, more accurate software, such as CarSim, is used to model the vehicle suspension dynamics and its nonlinearities. Finally, a commercial MR-damper could be used for the Hardware-inthe-Loop which includes physical constraints and allows to test the transient response when a control system is computed.

\section{Data Availability}

The Matlab/Simulink data used to support the findings of this study are available from the corresponding author upon request.

\section{Consent}

Informed consent was obtained from all the subjects involved in the study.

\section{Conflicts of Interest}

The authors declare no conflicts of interest.

\section{Authors' Contributions}

Conceptualization was done by R. A. R.-M. and C. S. D.-C; methodology was developed by L. C. F.-H.; resources were provided by R. A. R.-M.; supervision was done by R. A. R.M.; experimentation was performed by C. S. D.-C.; validation was performed by C. S. D.-C. and L. C. F.-H; original draft was written by C. S. D.-C. and R. A. R.-M; reviewing and editing were done by R. A. R.-M. and L. C. F.-H. All the authors have read and agreed to the published version of the manuscript.

\section{Acknowledgments}

The current project was funded by Tecnologico de Monterrey and Fundación FEMSA (Grant no. 0020206BB3, CAMPUSCITY Project).

\section{References}

[1] J. Wu, H. Zhou, Z. Liu, and M. Gu, "A load-dependent PWA$\mathrm{H} \infty$ controller for semi-active suspensions to exploit the performance of MR dampers," Mechanical Systems and Signal Processing, vol. 127, pp. 441-462, 2019.

[2] M. M. Morato, O. Sename, L. Dugard, and M. Q. Nguyen, "Fault estimation for automotive Electro-Rheological dampers: LPV-based observer approach," Control Engineering Practice, vol. 85, pp. 11-22, 2019.
[3] J. Wu, H. Zhou, Z. Liu, and M. Gu, "Ride comfort optimization via speed planning and preview semi-active suspension control for autonomous vehicles on uneven roads," IEEE Transactions on Vehicular Technology, vol. 69, no. 8, pp. 8343-8355, 2020.

[4] G. R. Worden and K. Tomlinson, Nonlinearity in Structural Dynamics,detection, Identification and Modeling, IoP Publishing, Bristol UK, 2000.

[5] B. F. Spencer, S. J. Dyke, M. K. Sain, and J. D. Carlson, "Phenomenological model for magnetorheological dampers," Journal of Engineering Mechanics, vol. 123, no. 3, pp. 230-238, 1997.

[6] W. Li, X. Dong, J. Yu, and J. X. C. Pan, "Vibration control of vehicle suspension with magneto- rheological variable damping and inertia," Journal of Intelligent Material Systems and Structures, 2021.

[7] S. D. Nguyen, B. D. Lam, and Q. H. Nguyen, "A fuzzy-based dynamic inversion controller with application to vibration control of vehicle suspension system subjected to uncertainties," Proceedings of the Institution of Mechanical Engineers - Part I: Journal of Systems \& Control Engineering, vol. 232, pp. 1103-1119, 2018.

[8] P. Hui, L. Fan, and X. Zeren, "Variable universe fuzzy control for vehicle semi-active suspension system with MR damper combining fuzzy neural network and particle swarm optimization," Neurocomputing, vol. 306, pp. 130-140, 2018.

[9] M. AbTalib and I. M. Darus, "Intelligent fuzzy logic with firefly algorithm and particle swarm opti- mization for semiactive suspension system using magneto-rheological damper," JVC/Journal of Vibration and Control, vol. 22, pp. 501-517, 2017.

[10] F. Meng and J. Zhou, "Modeling and control of a shear-valve mode MR damper for semiactive vehicle suspension," Mathematical Problems in Engineering, vol. 2019, no. 6, 8 pages, Article ID 2568185, 2019.

[11] F. Auino, A. Montiel, L. Flores, M. Larios, and C. Amado, "Modern semi-active control schemes for a suspension with MR actuator for vibration attenuation," Actuators, vol. 22, pp. 1-23, 2021.

[12] J. Ramamurthy and S. Choi, "A novel semi-active control strategy based on the cascade quan- titative feedback theory for a vehicle suspension system," Proceedings of the Institution of Mechanical Engineers - Part D: Journal of Automobile Engineering, vol. 233, pp. 1851-1863, 2019.

[13] X. Tang, H. Du, S. Sun, D. Ning, Z. Xing, and W. Li, “Takagisugeno fuzzy control for semi- active vehicle suspension with a magnetorheological damper and experimental validation," IEEE, vol. 22, pp. 291-300, 2017.

[14] M. Cheng and X. Jiao, "Modified active disturbance rejection control for non-linear semi-active ve- hicle suspension with magneto-rheological damper," Transactions of the Institute of Measurement and Control, vol. 40, pp. 2611-2621, 2018.

[15] M. Haddar, R. Chaari, S. Baslamisli, and F. Chaari, "Comparison between the effect of magne- torheological damper force and a system equipped with ADRC," in Proceedings of the 2nd International Conference on Advanced Materials, Mechanics and Manufacturing, A3M 2018. Lecture Notes in Mechanical Engineering, pp. 158-165, Springer, Hammamet, Tunisia, 2020.

[16] Y. Peng, M. Yu, X. Xu, X. Du, and J. Fu, "Fault detection and fault tolerant control of vehicle semi-active suspension system with magnetorheological dampers," in Proceedings of the 8th Conference on Smart Structures and Materials, SMART 2017 and 6th International Conference on Smart Materials and 
Nanotechnology in Engineering, pp. 115-128, Sanya, China, March 2017.

[17] A. Bashir, X. Rui, L. Abbas, and O. Zhou, "MR-damper vehicle suspension ride comfort enhancement based on advanced proportional-integral-differential sliding mode control," Control Engineering and Applied Informatics, vol. 20, pp. 11-21, 2018.

[18] A. Soosairai, "Second-order sliding mode controller for performance analysis of quarter car magnetorheological suspension system," SAE Technical Papers, vol. 2, p. 8, 2020.

[19] M. Ghoniem, T. Awad, and O. Mokhiamar, "Control of a new low-cost semi-active vehicle suspension system using artificial neural networks," Alexandria Engineering Journal, vol. 59, pp. 4013-4025, 2020.

[20] G. Tharehallimata and V. Mokenapalli, "Evaluation of on-off semi-active vehicle suspension systems by using the hardware-in-the-loop approach and the software-in-the-loop approach, "Transverse dynamic analysis of semi-active quarter car model controlled with an optimal conventional controller," International Journal of Vehicle Performance, vol. 6 , pp. 310-326, 2020.

[21] K. Hemanth, H. Kumar, and K. Gangadharan, "Vertical dynamic analysis of a quarter car suspension system with MR damper," Journal of the Brazilian Society of Mechanical Sciences and Engineering, pp. 41-51, 2017.

[22] Y. Peng, M. Yu, X. Du, X. Xu, and J. Fu, “An experimental study of vehicle suspension semi- active control with skyhook controller and magneto-rheological dampers," in Proceedings of the 29th Chinese Control and Decision Conference, pp. 7427-7429, Chongqing, China, May 2019.

[23] R. Sastry, K. Ramanaa, and M. Raob, "Analysis and prediction of performance of MR damper at different currents and control strategies for quarter suspension system of a roadway vehicle," International Journal of Vehicle Structures \& Systems, vol. 11, pp. 27-32, 2019.

[24] A. Bashir, X. Rui, and J. Zhang, "Ride comfort improvement of a semi-active vehicle suspension based on hybrid fuzzy and fuzzy-PID controller," Studies in Informatics and Control, vol. 28, pp. 421-430, 2019.

[25] A. Raj, S. Jumar, and Trikande, "Experimental evaluation of fuzzy controller for magnetorheolog-ical damper semi-active suspension system," in Proceedings of the IEEE International Conference on Signal Processing, Informatics, Communication and Energy Systems, IEEE, Kollam, India, August 2017.

[26] A. Turnip and J. Panggabean, "Hybrid controller design based magneto-rheological damper lookup table for quarter car suspension," International Journal of Artificial Intelligence, vol. 18, pp. 193-206, 2020.

[27] E. Palomares, J. Bellido, A. Morales, A. Nierto, and J. C. Pintado, "Pointwise-constrained optimal control of a semiactive vehicle suspension," Optimal Control Applications and Methods, vol. 42, pp. 216-235, 2021.

[28] S. Sha, Z. Wang, and H. Du, "Research on performance of vehicle semi-active suspension applied magnetorheological damper based on linear quadratic Gaussian control," Noise \& Vibration Worldwide, vol. 51, pp. 119-126, 2020.

[29] K. Oliveira, M. Braz-César, and J. Goncalvez, "Development of an optimal and fuzzy semi- active control system for vehicle suspension," in Proceedings of the 6th International Conference on Computational Methods in Structural Dynamics and Earthquake Engineering, pp. 3134-3143, Rhodes Island, Greece, June 2017.
[30] I. Angelov, "Optimal control synthesis of semi active vehicle suspension," Optimal Control Synthesis of Semi Active Vehicle Suspension, vol. 618, 2019.

[31] W. Baig, Z. Hou, and S. Ijaz, "Fractional order controller design for a semi-active suspension system using NelderMead optimization," in Proceedings of the 29th Chinese Control and Decision Conference, pp. 2808-2813, Changqing, China, May 2017.

[32] O. Ghasemalizadeh, S. Taheri, A. Singh, and K. B. Singh, "Analysis and enhancement of hybrid skyhook-groundhook for optimal performance," ASME Digital Collection, vol. 1, 2017.

[33] M. Sergio, E. Silani, and S. Bittanti, "Acceleration-drivendamper ADD: an optimal control algorithm for comfortoriented semiactive suspensions," ASME Digital Collection, vol. 127, no. 2, 2005.

[34] C. Poussot-Vassal, O. Sename, L. Dugard, R. R. Mendoza, and L. Flores, "Optimal skyhook control for semi-active suspension," Institutlo Tecnológico y de Estudios Superiores Monterrey, vol. 39, no. 16, pp. 608-613, 2006.

[35] L. Flores, A. Drivet, R. Ramírez-Mendoza, O. Sename, C. P. Vassal, and L. Dugar, "Hybrid optimal control for semiactive suspension systems," in Proceedings of the 10th MINI conference on Vehicle System Dynamics, Identification and Anomalies, VSDIA, Budapest, Hungary, November 2006.

[36] O. Ahmad, Moaaz, and N. M. Ghazaly, "Semi-active suspension," International Journal of Adavanced Science and Technology, vol. 28, no. 18, pp. 424-433, 2019.

[37] R. M. Yerge, P. D. Shendge, V. Paighan, and S. B. Phadke, "Design and implementation of a two objective active suspension using hybrid skyhook and groundhook strategy," in Proceedings of the IEEE International Conference on Recent Trends in Electronics Informatino \& Communication Technology, IEEE, Bangalore, India, May 2017.

[38] T. Sireteanu, D. Stancioiu, and C. Stammers, "Modelling of magnetorheological fluid dampers," in Proceedings of the Romanian Academ: Series A, vol. 2, no. 3, pp. 105-113, 2001.

[39] H. Lam, C. Lai, and W. Liao, Automobile Suspension Systems with MR Fluid Dampers, Technical Report, Department of Mechanical and Automation Engineering, The Chinese University of Hong Kong, Hong Kong, China, 2002.

[40] F. D. Goncalves, "Dynamic analysis of semi-active control techniques for vehicle applications," Virginia Polytechnic Institute and State University, vol. 1, 2001.

[41] Y. Wen, "Method for random vibration of hysteretic systems," ASCE Journal of the Engineering Mechanics Division, vol. 102, no. 2, pp. 249-263, 1976.

[42] L.C. Félix-Herrán, "Modeling and control of an automotive suspension with magneto-rheological dampers," Instituto Tecnológico y de Estudios Superiores de Monterrey, vol. 1, 2011.

[43] C. Poussot-Vassal, O. Sename, L. Dugard, Z. Szabó, and J. Bokor, "A new semi-active suspension control strategy through LPV technique," Journal of Control Engineering Practice, vol. 16, pp. 1519-1534, 2008.

[44] D. Sammier, O. Sename, and L. Dugard, "Skyhook and H control of semi-active suspensions: some practical aspects," Vehicle System Dynamics, pp. 279-308, 2003.

[45] J. Y. Wong, Theory of Ground Vehicles, Wiley, New York, NY, USA, 2001.

[46] L. C. Félix-Herrán, D. Mehdi, J. J. Rodríguez-Ortiz, V. H. Benitez, R. A. Ramírez-Mendoza, and R. Soto, "Disturbance rejection in a one-half semiactive vehicle suspension by means of a fuzzy-Ho controller," Shock and Vibration, vol. 2019, Article ID 4532635, 14 pages, 2019. 
[47] D. Ciampa, S. Olita, and M. Agostinacchio, The Vibrations Induced by Surface Irregularities in Road Pavements - a Matlab Approach, Springer, New York, NY, USA, 2013.

[48] S. Wu, C. Wu, and T. Lee, "Neural-network-based optimal fuzzy control design for half-car active suspension systems," in Proceedings of the IEEE Intelligent Vehicles Symposium, pp. 376-381, Las Vegas, NJ, USA, June 2005.

[49] J. J. Slotine and W. Li, Applied Nonlinear Control, PrenticeHall, Hoboken, NJ, USA, 1991.

[50] L. CurielRamirez, R. A. Ramirez-Mendoza, J. IzquierdoReyes, M. R. Bustamante-Bello, and S. A. Navarro-Tuch, "The loop frame- work proposal for a semi-autonomoues car architecture in a closed route envonment," International Journal on Interactive Design and Manufacturing, 2019.

[51] J. Lozoya-Santos, R. Morales-Menendez, and R. A. RamirezMendoza, "Evaluation of on-off semi-active vehicle suspension systems by using the hardware-in-the-loop approach and the software-in-the-loop approach," Proceedings of the Institution of Mechanical Engineers, Part D: Journal of Automobile Engineering, vol. 229, no. 1, pp. 52-69, 2014. 